\title{
Die Bedeutung des Prager Traditionsrezesses von 1635 für die rechtliche Sonderstellung der Oberlausitz im Königreich Sachsen (1806-1918)
}

\author{
von \\ FRANK METASCH
}

Nach der Bedeutung des Prager Traditionsrezesses von 1635 für die rechtliche Sonderstellung der Oberlausitz im Königreich Sachsen zu fragen, wirkt auf den ersten Blick anachronistisch. Schließlich gehört es in der sächsischen Landesgeschichte zu den gängigen Auffassungen, dass 1806 mit dem Ende des Alten Reichs und der Erhebung Sachsens zu einem souveränen Königreich, spätestens aber mit der sächsischen Verfassung von 1831 auch der Traditionsrezess und damit die lehnsrechtliche Bindung der Oberlausitz an Böhmen erloschen ist. Im Gegensatz $\mathrm{zu}$ dieser Sichtweise bestand die Habsburgermonarchie aber bis zu ihrer Abdankung 1918 offiziell weiterhin auf ihren 1635 verbrieften Rechten, und auch aus der Perspektive sächsischer Juristen und Staatsrechtler ${ }^{1}$ - darunter selbst des Wettiners Max von Sachsen (1870-1951) als Angehörigem des regierenden Fürstenhauses stellte sich das Erlöschen des Traditionsrezesses keinesfalls so eindeutig dar wie für viele sächsische Politiker oder Historiker.

Vereinzelt finden sich aber auch in der landesgeschichtlichen Literatur Stimmen, die darauf verweisen, dass die Bestimmungen des Prager Traditionsrezesses noch nach 1831 eine eminente Rolle für die Sonderstellung der Oberlausitz spielten $^{2}$ - eine Sonderstellung, die eben nicht, wie so oft in der Landesgeschichte

1 Vgl. Julius Pfeiffer, Das Verhältniß der Oberlausitz zur Krone Böhmen. Ein Beitrag zur Geschichte der Lausitz, in: Neues Lausitzisches Magazin 50 (1873), S. 77-101; Heinrich Deumer, Der rechtliche Anspruch Böhmen-Österreichs auf das Königlich Sächsische Markgrafthum Oberlausitz. Eine Staatsrechtliche Deduction unter Benutzung archivalischer Quellen, Leipzig 1884; MAx Herzog Zu SACHSEN, Die staatsrechtliche Stellung des Königlich Sächsischen Markgrafentums Oberlausitz, Leipzig [1892]. Mit großem zeitlichen Abstand zuletzt auch: Hans-Wolf Thümmel, Wem gehört die Oberlausitz? Anmerkungen aus verfassungsrechtlicher Sicht, in: Matthias Theodor Vogt/Jan Sokol/Eugeniusz Tomiczek (Hg.), Kulturen in Begegnung, Wrocław/Görlitz 2004, S. 41-70.

2 Vgl. insbesondere Uwe Lammel, Das Haus Habsburg und die Oberlausitz nach 1635, in: Joachim Bahlcke/Volker Dudeck (Hg.), Welt - Macht - Geist. Das Haus Habsburg und die Oberlausitz 1526-1635, Görlitz 2002, S. 231-240; Gerhard SCHMidT, Die Einschränkung der rechtlichen Sonderstellung der sächsischen Oberlausitz im 19. Jahrhundert, in: Lětopis. Jahresschrift des Instituts für sorbische Volksforschung B/24 (1977), S. 51-83; Heinrich Herzog, Die rechtliche Sonderstellung der Oberlausitz in der sächsischen Landeskirche, in: Herbergen der Christenheit. Jahrbuch für deutsche Kirchengeschichte 2 (1959), S. 71-95. 
angemerkt, 1831 endete, sondern die vor allem im Kirchenwesen und in der Gesetzgebung noch Anfang des 20. Jahrhunderts trotz aller Einschränkungen so weitreichend war, dass die Oberlausitz noch immer als ein Staat im Staate Sach$\operatorname{sen}^{3}$ wahrgenommen worden ist. Im Folgenden soll daher anhand der Integration der Oberlausitz in den sächsischen Gesamtstaat der Frage nachgegangen werden, ob der Prager Traditionsrezess, beziehungsweise die darin formulierten Vertragsbedingungen, auch über 1806 und 1831 hinaus noch eine politische Bedeutung besaßen. Hierbei kann kein Anspruch erhoben werden, das Thema erschöpfend zu behandeln, es soll vielmehr mittels ausgewählter Beispiele hinterfragt werden, inwieweit in den politischen Diskursen des 19. und beginnenden 20. Jahrhunderts nicht doch noch auf den Traditionsrezess rekurriert worden ist.

\section{Der Prager Traditionsrezess}

Gut zwei Jahrhunderte lang regelte der Prager Traditionsrezess die staatsrechtliche Stellung der beiden Markgraftümer der Ober- und Niederlausitz innerhalb des sächsischen Staatsverbandes, sodass zumindest kurz auf das Zustandekommen und den Inhalt dieses „Staatsgrundgesetzes“4 der Lausitzen eingegangen werden soll: 5

Im Dreißigjährigen Krieg nahm das Kurfürstentum Sachsen unter Johann Georg I. (reg. 1611-1656) als führender evangelischer Reichsstand lange Zeit eine „Schlüsselrolle“ ein. 6 Trotz seines eigenen Bekenntnisses versuchte der sächsische

3 Vgl. H[einrich] J[ohannes] Scheuffler, Ein Staat im Staate Sachsen, in: Dresdner Anzeiger. Sonntagsbeilage 7 (1907), Nr. 6, S. 22 f., Nr. 7, S. 30-32.

4 So eingestuft von: Max Herzog zu Sachsen, Staatsrechtliche Stellung des Markgraftums Oberlausitz (wie Anm. 1), S. 3.

5 Der Prager Traditionsrezess ist fester Bestandteil der landesgeschichtlichen Literatur zur Oberlausitz, sodass hier nur einige ausführlichere Beispiele genannt seien: zum Zustandekommen vgl. insbesondere Ellen Franke, Die Abtretung der Lausitzen an Kursachsen während des Dreißigjährigen Krieges aus der Wiener Perspektive, in: Heinz-Dieter Heimann/Klaus Neitmann/Uwe Tresp (Hg.), Die Nieder- und Oberlausitz. Konturen einer Integrationslandschaft, Bd. 2: Frühe Neuzeit (Studien zur brandenburgischen und vergleichenden Landesgeschichte 12), Berlin 2014, S. 91-106; Frank MüLLER, Kursachsen und der Böhmische Aufstand 1618-1622 (Schriftenreihe der Vereinigung zur Erforschung der neueren Geschichte 23), Münster 1997. Ausführlich zum Inhalt vgl. z. B. Max Herzog zu SAchsen, Staatsrechtliche Stellung des Markgraftums Oberlausitz (wie Anm. 1), S. 3-6; L. Grosse, Entwicklung der Verfassung und des öffentlichen Rechts der Niederlausitz seit dem Traditions-Recesse im Jahre 1635, in: Neues Lausitzisches Magazin 55 (1879), S. 1-264, hier S. 2-5. Kommentierte Edition: Kathrin Bierther (Bearb.), Die Politik Maximilians I. von Bayern und seiner Verbündeten 1618-1651, Teil 2, Bd. 10: Der Prager Frieden von 1635, Teilbd. 4: Vertragstexte, Wien 1997, Nr. 564B, S. 1631-1640.

6 Zur Biografie Johann Georgs I. sowie seiner Rolle im Dreißigjährigen Krieg vgl. AxEL GotTHARD, Johann Georg I. (1611-1656), in: Frank-Lothar Kroll (Hg.), Die Herrscher Sachsens. Markgrafen, Kurfürsten, Könige 1089-1918, München 22013, S. 137-147, 335, Zitat $=$ S. 137. Allgemein zur sächsischen Politik im Dreißigjährigen Krieg vgl. auch 
Kurfürst, seine politischen Ziele in Anlehnung an das katholische Kaiserhaus durchzusetzen. Grundlage für diese schon zeitgenössisch kritisierte Gratwanderung zwischen evangelischer Führungsposition und Kaisertreue war bereits seit Kurfürst August (reg. 1553-1586) eine strikte Entkonfessionalisierung der sächsischen Außenpolitik. Auch den in Böhmen 1618 mit dem Prager Fenstersturz ausgebrochenen Aufstand der protestantischen Stände wertete Kursachsen daher nicht als konfessionellen Konflikt, sondern als illegitimen politischen Umsturzversuch. Mit dieser entkonfessionalisierten Lesart war es dem sächsischen Kurfürsten möglich, auch als evangelische Schutzmacht den katholischen Kaiser und böhmischen König Ferdinand II. (reg. 1617/19-1637) zu unterstützen und als kaiserlicher Kommissar die böhmischen Nebenlande der Markgraftümer Oberund Niederlausitz sowie des Herzogtums Schlesien militärisch zu unterwerfen.7 Als Gegenleistung für seine finanziellen Aufwendungen hatte Johann Georg I. gefordert, ihm bis zu deren Begleichung die beiden Lausitzen zu verpfänden. Da Ferdinand II. die erforderliche Summe von fast 4 Millionen Gulden nicht aufzubringen vermochte, setzte er Kursachsen mit den Immissionsrezessen vom 23. und 30. Juni 1623 in den Pfandbesitz der Ober- und Niederlausitz. ${ }^{8}$

Erst das kaiserliche Restitutionsedikt vom 6. März 1629 - mit der auch an Kursachsen gerichteten Forderung, alle seit dem Passauer Vertrag von 1552 säkularisierten Kirchengüter in ihren alten Bestand zurückzusetzen - führte zum politischen Kurswechsel. Johann Georg I. begab sich allerdings nicht direkt auf eine Seite der Krieg führenden Parteien, sondern versuchte, im Reich eine dritte Kraft zu formieren. Mit dem sächsisch-schwedischen Bündnis vom 11. September 1631 wurde Kursachsen dann doch noch aktiv in die Kriegshandlungen einbezogen. Bereits Ende 1631 nahm Sachsen wieder erste Sondierungsgespräche mit dem habsburgischen Hof auf und verhandelte dann ab Juni 1634 aktiv über einen Friedensvertrag. Auch in den hierbei geführten „zähen Verhandlungen“ verknüpfte der sächsische Kurfürst erneut seine eigenen territorialen Interessen auf das Engste mit den allgemeinen reichspolitischen Zielen. ${ }^{9}$

Johannes Burkhardt, Der Dreißigjährige Krieg und die sächsische Politik, in: Bahlcke/Dudeck, Das Haus Habsburg und die Oberlausitz (wie Anm. 2), S. 221-230; Frank Müller, Der Absturz vom Grat. Die Niederlage der kursächsischen Deeskalationsstrategie nach dem Ausbruch des Dreißigjährigen Krieges, in: Winfried Schulze (Hg.), Friedliche Intentionen - Kriegerische Effekte. War der Ausbruch des Dreißigjährigen Krieges unvermeidlich? (Studien zur neueren Geschichte 1), St. Katharinen 2002; Axel GotThard, „politice seint wir bäpstisch“. Kursachsen und der deutsche Protestantismus im frühen 17. Jahrhundert, in: Zeitschrift für historische Forschung 20 (1993), S. 275-319.

7 Grundlegend: MüLlER, Kursachsen und der Böhmische Aufstand (wie Anm. 5). Darauf basierend: WINFRIEd MülleR, Die Oberlausitz in der Frühen Neuzeit (1526-1815), in: Ders. u. a., Oberlausitz (Kulturlandschaften Sachsens 4), Leipzig 2011, S. 57-96, hier S. 74-79.

8 Vgl. Müller, Kursachsen und der Böhmische Aufstand (wie Anm. 5), S. 458-462.

9 Vgl. auf der Grundlage der Wiener Quellenüberlieferung mit neuen, über den bisherigen Stand der Landesgeschichte hinausgehenden Erkenntnissen: Franke, Abtretung der Lausitzen (wie Anm. 5). 
Obwohl die sächsische Forderung nach einer Abtretung beider Lausitzen aus kaiserlicher Sicht völlig überzogen war, musste Ferdinand II. - der durch das drohende militärische Eingreifen Frankreichs unter Druck stand und der sich bewusst war, dass ohne den Ausgleich mit Sachsen sowohl der große Frieden im Reich als auch die erhoffte Wahl seines Sohnes zum deutschen König kaum durchsetzbar wären - letzten Endes doch nachgeben. Um ein dauerhaftes politisches Absinken seines Hauses abzuwenden, opferte der Habsburger zur „Stabilisierung der Reichsverfassung“ die Lausitzen und damit sein „geostrategisches [...] Sprungbrett nach Mitteldeutschland“. 10

Da die kaiserliche Seite für die aufgelaufenen Schulden in Höhe von 72 Tonnen Gold (die Tonne zu 100000 Reichstaler gerechnet) lange Zeit nur eines der beiden Markgraftümer hergeben wollte, ist die erzielte Abtretung beider Lausitzen als ein beachtenswerter Verhandlungserfolg Sachsens zu werten. Einige Abstriche musste Johann Georg I. trotzdem hinnehmen: So war der Kaiser weder auf eine Belehnung des gesamten Hauses Wettin noch auf eine vollständige Entschuldung der Lausitzen eingegangen. ${ }^{11}$

Mit der Unterzeichnung des Prager Friedens, ${ }^{12}$ von dem man in Dresden erhoffte, er würde sich durch den Beitritt der anderen Reichsstände zu einem allgemeinen Reichsfrieden erweitern, beendete Kursachsen am 30. Mai 1635 das Bündnis mit Schweden und schloss Frieden mit dem Kaiser. In einer Nebenvereinbarung zum Prager Frieden - dem sogenannten Prager Traditionsrezess ${ }^{13}$ - wurden die 1634 ausgehandelten Bedingungen zur Übertragung der beiden Lausitzen festgehalten. Die förmliche Übergabe durch kaiserliche Kommissare erfolgte dann mit den sogenannten Traditionsabschieden für die Oberlausitz am 24. April 1636 in Görlitz und für die Niederlausitz am 30. Mai 1636 in Guben. ${ }^{14}$

Die für die folgenden Erörterungen relevanten Punkte des Traditionsrezesses ${ }^{15}$ betrafen an erster Stelle die böhmische Oberlehnsherrschaft, denn auch wenn der Kaiser dem sächsischen Kurfürsten die beiden Markgraftümer samt allen Hoheitsrechten und Regalien erblich, eigentbümblich und unwiderrufflich abtrat (Absatz 1), so sollten diese doch lehnsrechtlich von dem königreich Böheim nicht abgeson-

10 Vgl. ebd., S. 99, 105 f.

11 Vgl. ebd., S. 103.

12 Zum Prager Frieden vgl. die oben in Anm. 5 bereits erwähnten vier Teilbände von Kathrin Bierther.

13 Vgl. oben, Anm. 5.

14 Zur anschließenden Erbhuldigung der Oberlausitzer Stände vgl. Siegrried Hoche, Die Erbhuldigung der Oberlausitzer Stände im Jahre 1637 in Görlitz im Spiegel der Quellen des Görlitzer Ratsarchives, in: Martin Schmidt (Hg.), Die Oberlausitz und Sachsen in Mitteleuropa. Festschrift zum 75. Geburtstag von Prof. Dr. Karlheinz Blaschke, Görlitz/Zittau 2003, S. 29-37. Die endgültige Belehnung durch Böhmen erfolgte 1638; Müller, Kursachsen und der Böhmische Aufstand (wie Anm. 5), S. 462. - In der Literatur werden Traditionsrezess und -abschied sehr oft verwechselt bzw. fälschlicherweise synonym verwendet.

15 Absatzzählung und Zitate nach: Bierther, Die Politik Maximilians I. von Bayern 2/10/4 (wie Anm. 5). 
dert, sondern demselben alß ein hobes und vornebmes stück [...] zugethan verbleiben (Absatz 12). Als sichtbaren Ausdruck hierfür behielten sich die Habsburger vor, weiterhin ebenfalls Titel und Wappen beider Markgraftümer zu führen (Absatz 4). Bei jedem Todesfall eines Lehnsmannes oder Lehnsherrn hatten die Wettiner binnen eines Jahres (innerbalb jars und tags) beim böhmischen König um eine Lehnserneuerung nachzusuchen (Absatz 8). Lehnsberechtigt waren alle männlichen Nachfahren Johann Georgs I. und nach deren Aussterben die sachsenaltenburgischen Herzöge, wobei die Lausitzen nicht geteilt, sondern immer nur geschlossen weitergegeben werden durften. Sollte auch die Altenburger Linie keine erbberechtigten Söhne mehr aufweisen - was bereits 1672 eintrat $^{16}$-, so hätte es den Habsburgern freigestanden, ob sie die Lausitzen gegen die Zahlung der geschuldeten Summe einlösen oder die Töchter Johann Georgs I. mit deren jeweiligen Nachkommen belehnen würden. Ganz am Ende der Erbfolge stand dann ein entschädigungsloses Heimfallrecht an die böhmische Krone (Absatz 5-7).

Von besonderer Bedeutung für die weitere Geschichte der Lausitzen gestaltete sich die Bestimmung, dass die Wettiner nicht in die bestehenden Verfassungs- und vor allem Religionsverhältnisse (Absatz 10) der Lausitzen eingreifen durften. Dieses Einfrieren der Verfassungs- und Religionsverhältnisse bezog sich vor allem auf den Schutz der katholischen Minderheit, da im Gegensatz zu den sächsischen Erblanden die Reformation den katholischen Glauben in den Lausitzen nicht gänzlich verdrängt hatte. ${ }^{17} \mathrm{Zu}$ Beginn des 17. Jahrhunderts existierten in der Niederlausitz noch das Kloster Neuzelle und in der Oberlausitz das Bautzener Domstift und -kapitel St. Petri, die drei Frauenklöster Marienstern, Marienthal und Lauban sowie dreizehn katholische Pfarrkirchen. Um diese, der eigenen Konfession angehörende Minderheit wirksam zu schützen, behielten sich die Habsburger

16 Mit dem frühen Tod des 1657 geborenen Friedrich Wilhelm III. starb 1672 die im Traditionsrezess angesprochene ernestinische Linie Sachsen-Altenburg aus; vgl. Отто Posse, Die Wettiner. Genealogie des Gesamthauses Wettin Ernestinischer und Albertinischer Linie mit Einschluß der regierenden Häuser von Großbritannien, Belgien, Portugal und Bulgarien. Mit Berichtigungen und Ergänzungen der Stammtafeln bis 1993, Reprint Leipzig 1994, Tafel 9. Die anderen ernestinischen Linien erhielten dadurch keinen Rechtsanspruch an den Lausitzen; vgl. Pfeiffer, Verhältnis der Oberlausitz zur Krone Böhmen (wie Anm. 1), S. 99.

17 Vgl. z. B. Helmut Flachenecker, Kirchliche Raumordnung im Spannungsfeld zwischen Beharrung und Wandel. Die Apostolische Administratur des Bistums Meißen in den Lausitzen, in: Heinz-Dieter Heimann/Klaus Neitmann/Thomas Brechenmacher (Hg.), Die Nieder- und Oberlausitz. Konturen einer Integrationslandschaft, Bd. 3: Frühes 19. Jahrhundert (Studien zur brandenburgischen und vergleichenden Landesgeschichte 13), Berlin 2014, S. 55-70; MüLler, Die Oberlausitz in der Frühen Neuzeit (wie Anm. 7), S. 64-74; Karlheinz Blaschke/Siegfried Seifert, Reformation und Konfessionalisierung in der Oberlausitz, in: Bahlcke/Dudeck, Das Haus Habsburg und die Oberlausitz (wie Anm. 2), S. 121-128. Speziell zum niederlausitzischen Kloster Neuzelle vgl. auch Winfried TöPleR, Der Kaiser vor Ort. Das Kloster Neuzelle als katholische Enklave in der Niederlausitz, in: Heimann/Neitmann/Tresp, Konturen einer Integrationslandschaft 2 (wie Anm. 5). 
die kirchlichen Oberaufsichts- und Visitationsrechte über die katholischen Einrichtungen vor. So hatten die Wahlen in den Klöstern und im Bautzener Domkapitel nicht nur im Beisein kaiserlicher Kommissare zu erfolgen, die Habsburger besaßen auch das Bestätigungsrecht für die gewählten geistlichen und weltlichen Amtsträger. Zudem durfte Sachsen die Inspektionen und Visitationen der drei zum Zisterzienserorden gehörenden Klöster Marienthal, Marienstern und Neuzelle, deren Ordensoberen ihren Sitz in Böhmen hatten, nicht behindern. Und während die Lausitzer Untertanen zukünftig nicht mehr an böhmische, sondern nur noch an sächsische Gerichte appellieren durften (Absatz 14-16), verfügten die sächsischen Gerichte über keine Befugnisse in geistlichen Angelegenheiten. ${ }^{18}$

Zusammenfassend bedeutete dies aus staatsrechtlicher Perspektive nicht, dass der Traditionsrezess prinzipiell Änderungen an der Landesverfassung ausschloss, diese hätten jedoch nur mit Zustimmung der Stände ${ }^{19}$ und im Bereich der Religionsverfassung mit Zustimmung des habsburgischen Lehnsherrn erfolgen dürfen. ${ }^{20}$ Allerdings sahen Stände und Lehnsherren - wie die verschiedenen Vorstöße der Wettiner, beispielsweise im erfolglosen Bestreben, ebenfalls ein Bestätigungsrecht für die katholischen Stiftswahlen zu erhalten, zeigen - keinen Anlass, freiwillig auf eine Einschränkung, sondern allenfalls auf eine Erweiterung ihrer Rechte und Privilegien einzugehen.

Die in der Literatur geführte Streitfrage, ob die Lausitzen denn mit dem Traditionsrezess 1635 ein Teil Kursachsens geworden sind oder nicht, ${ }^{21}$ dürfte auf die unterschiedlichen zugrunde gelegten Definitionen zurückzuführen sein. Wenn unter Kursachsen nur die sächsischen Erblande mit dem Kurkreis verstanden werden, dann gehörten die Ober- und die Niederlausitz als sächsische Nebenlande nicht dazu. Wenn aber darunter - wie auch im Folgenden - alle unter die Landesherrschaft der Wettinern gefallenen Landesteile gemeint sind, dann sind die Lausitzen natürlich auch ein Teil des Kurstaates. Sie waren aber kein Teil der Erblande und sie unterstanden auch nicht dem sächsischen Kurfürsten, sondern seinem in Personalunion geführten Amt als Markgraf der Ober- beziehungsweise der Niederlausitz. ${ }^{22}$

18 Vgl. Thümmel, Wem gehört die Oberlausitz (wie Anm. 1), S. 54.

19 Einen Überblick zur Geschichte der Lausitzer Stände bietet: AnJa MoschKe, Zur Geschichte der Oberlausitzer Ständeversammlung, in: Silke Kosbab/Anja Moschke/ Almut Natuschke, LandStändeHäuser in Bautzen. Zur Geschichte des Bautzener und des Görlitzer Landhauses auf der Schloßstraße (Schriftenreihe des Archivverbundes 1), hrsg. vom Archivverbund Bautzen, Bautzen 2011, S. 13-27.

20 Vgl. Max Herzog zu Sachsen, Staatsrechtliche Stellung des Markgraftums Oberlausitz (wie Anm. 1), S. 5, 13.

21 Vgl. z. B. Thümmel, Wem gehört die Oberlausitz (wie Anm. 1), S. 50.

22 Dass diese Unterscheidung den lausitzischen Ständen wichtig war, zeigte sich beispielsweise schon unter Johann Georg II. (reg. 1656-1680), als eine stärkere Betonung der kurfürstlichen Würde auf den sächsischen Taler-Münzen ihren „Widerspruch“ hervorrief; vgl. PAul ARnold, Die sächsische Talerwährung von 1500 bis 1763, in: Schweizerische Numismatische Rundschau 59 (1980), S. 50-94, hier S. 83 f. 


\section{Zwischen Rétablissement und Rheinbund 1762/63-1806}

Wie bereits das Beispiel der Lausitzen zeigt, bildete das frühneuzeitliche Kursachsen keinen einheitlichen Staat. Noch im ersten Drittel des 19. Jahrhunderts setzte sich das Land aus vielen einzelnen Gebieten mit unterschiedlichen Territorialverfassungen zusammen. ${ }^{23}$ Diese einzelnen Landesteile waren nur mehr oder weniger lose miteinander verbunden und betrachteten sich gegenseitig oftmals als Ausland. ${ }^{24}$ Auch die Ober- und Niederlausitz waren als größte und wichtigste Nebenländer, wie bereits angesprochen, nur in Personalunion mit den sächsischen Erblanden verbunden. Beide Markgraftümer verfügten weiterhin über eigene Stände, Behörden und Gesetze - die Besonderheiten der verschiedenen lausitzischen Standesherrschaften gar nicht mitgerechnet.

Entsprechend schwierig gestaltete sich die Verwaltung des sächsischen Gesamtstaates, wenn beispielsweise die sächsischen Zentralbehörden bei der Gesetzgebung oder der Steuererhebung allein sieben verschiedene Ständeversammlungen einbeziehen mussten. ${ }^{25} \mathrm{Nicht}$ von ungefähr galt daher die unübersichtliche sächsische Staatsverfassung und -verwaltung noch zu Beginn des 19. Jahrhunderts als wichtigster Reformpunkt. Und genau hier, auf dem Weg zum konstitutionellen Einheitsstaat, sollte sich der Traditionsrezess als Hürde erweisen, konnten doch in den Lausitzen ohne Zustimmung der dortigen Provinzialstände keine Verfassungsänderungen vorgenommen werden.

$\mathrm{Da}$ es in Sachsen zwischen den beiden großen Staatsreformen der 1760er- und 1830er-Jahre keine relevanten Veränderungen an der Territorialverfassung gegeben hat, könnte schnell der falsche Eindruck entstehen, der Traditionsrezess wäre wirklich bedeutungslos geworden. Bezeichnenderweise wird der Zeitraum zwischen dem Rétablissement von 1762/63 und der sächsischen Verfassung von 1831 in der Forschung als eine Zeit des inneren Stillstands und der politischen Stagnation charakterisiert. ${ }^{26}$ Diese Resignation vor dem politischen Stillstand in Sachsen

23 Vgl. Gerhard Schmidt, Die Staatsreform in Sachsen in der ersten Hälfte des 19. Jahrhunderts. Eine Parallele zu den Steinschen Reformen in Preußen (Schriftenreihe des Staatsarchivs Dresden 7), Weimar 1966, S. 28-48; Karlheinz BlaschKe/Werner Stams, Das Kurfürstentum Sachsen am Ende des Alten Reiches 1790-1806 (Atlas zur Geschichte und Landeskunde von Sachsen. Beiheft zur Karte C III 5), Leipzig/Dresden 2007, S. 8-13.

24 Zur Frage der Landeszugehörigkeit der sächsischen Untertanen und zur Herausbildung einer sächsischen Staatsangehörigkeit im 19. Jahrhundert vgl. am besonderen Beispiel der Oberlausitz: LuTz Vogel, Aufnehmen oder abweisen? Kleinräumige Migration und Einbürgerungspraxis in der sächsischen Oberlausitz 1815-1871 (Schriften zur sächsischen Geschichte und Volkskunde 47), Leipzig 2014, S. 33-88.

25 Vgl. Gerhard Schmidt, Zur Staats- und Verwaltungsreform nach 1830, in: Dresdner Hefte 26 (1991), S. 47-52, hier S. 47; Ders., Staatsreform in Sachsen (wie Anm. 23), S. $40-43$.

26 Vgl. z. B. Winfried Müller, Zwischen Stagnation und Modernität: Sachsens Weg zur Verfassung von 1831, in: Alois Schmid (Hg.), Die bayerische Konstitution von 1808. Entstehung - Zielsetzung - Europäisches Umfeld (Zeitschrift für bayerische Landesgeschichte, Beiheft 35), München 2008, S. 179-210; Karlheinz Blaschke, Sachsen zwi- 
Frank Metasch

bezog sich vor allem auf den reformunwilligen, streng konservativen Kurfürsten Friedrich August III., seit 1806 König Friedrich August I. (reg. 1763/68-1827). ${ }^{27}$ Im Gegensatz zu den fehlenden Reformumsetzungen existierte im Land aber ein reger politischer Gestaltungswille.

Bereits die Staatsreformer des Rétablissements ${ }^{28}$ betrachten die der politischen Modernisierung im Wege stehende, uneinheitliche Territorialverfassung als nicht mehr zeitgemäß. Vor allem vor dem Hintergrund der im Zuge der Französischen Revolution herüberkommenden, neuen politischen Theorien - darunter auch neue Raumkonzepte ${ }^{29}$ - wurden die sächsischen Verhältnisse zunehmend kritisiert, und es kam zu einer Vielzahl von Reformvorschlägen und -projekten. ${ }^{30}$ Die politischen Debatten blieben dabei keinesfalls nur auf die sächsischen Landtage, als dem zentralen Ort des politischen Diskurses, beschränkt. Insbesondere die rege Publikation von Druckschriften, die die Landtagsverhandlungen begleitete und die sich zwischen 1793 und 1805 zu einem regelrechten „Broschürenstreit“ ausweitete, erreichte über den engen Rahmen der Landstände hinaus eine breite Öffentlichkeit.

Doch obwohl Sachsen mit seinem auf den modernen Gesellschaftstheorien fußenden Reformdiskurs „zu einem vielbeachteten Experimentierfeld innerhalb des Reiches“ avancierte und selbst im Fokus französischer Zeitschriften stand, ${ }^{31}$ blieb gerade im Bereich der Territorialverfassung alles beim Alten. Die zur Über-

schen den Reformen 1763 bis 1831, in: Uwe Schirmer (Hg.), Sachsen 1763-1832. Zwischen Rétablissement und bürgerlichen Reformen (Schriften der Rudolf-KötzschkeGesellschaft 3), Beucha 22000, S. 9-23.

27 Zur Biografie Friedrich Augusts vgl. Winfrid Halder, Friedrich August III./I. 1763/1806-1827, in: Kroll, Die Herrscher Sachsens (wie Anm. 6), S. 203-222, 341-343; Dorit Petschel, Sächsische Außenpolitik unter Friedrich August I. Zwischen Rétablissement, Rheinbund und Restauration (Dresdner Historische Studien 4), Köln/ Weimar/Wien 2000.

28 Vgl. Winfried Müller, Das sächsische Rétablissement nach 1763. Ziele und Grenzen einer Staatsreform, in: Dresdner Hefte 114 (2013), S. 14-24; sowie immer noch grundlegend: Horst Schlechte, Die Staatsreform in Kursachsen 1762-1763. Quellen zum kursächsischen Rétablissement nach dem Siebenjährigen Kriege (Schriftenreihe des Sächsischen Landeshauptarchivs Dresden 5), Berlin 1958.

29 Vgl. StefFen SAmmler, Territorialstaat oder Region? Die Konstruktion des sächsischen Raumes im Zeitalter der Aufklärung (1763-1811), in: Anneliese Klingenberg u. a. (Hg.), Sächsische Aufklärung (Leipziger Studien zur Erforschung von regionenbezogenen Identifikationsprozessen 7), Leipzig 2001, S. 49-72; sowie die aktuell am Institut für Sächsische Geschichte und Volkskunde vor dem Abschluss stehende Dissertation: Henrik Schwanitz, Von der Natur gerahmt. Die Idee der „natürlichen Grenzen“ als Identitätsressource um 1800.

30 Vgl. SAmmler, Territorialstaat oder Region (wie Anm. 29), z. B. S. 50 f., 63 f.; Gerhard Schmidt, Reformbestrebungen in Sachsen in den ersten Jahrzehnten des 19. Jahrhunderts (Quellen und Forschungen zur sächsischen Geschichte 7), Dresden 1969, S. 22-24; Ders., Staatsreform in Sachsen (wie Anm. 23), S. 56 f.

31 Zitat = SAmmlen, Territorialstaat oder Region (wie Anm. 29), S. 51; vgl. auch Schwanitz, Die Idee der „natürlichen Grenzen“ (wie Anm. 29), insbesondere die Erörterungen zum sächsischen Landtag von 1811. 
windung der gewaltigen Kriegsschäden angelegte Konzentration des Rétablissements auf das Wirtschafts-, Finanz- und Bildungswesen, ließ die fehlende Landeseinheit in den Hintergrund rücken. Nur punktuell wurden Vorschläge für Vereinheitlichungen unterbreitet, so etwa schon 1762 die nicht umgesetzte Empfehlung, die Lausitzen wenigstens beim Abzugsgeld nicht mehr als Ausland zu betrachten. ${ }^{32}$ Denn da die Erblande und die Lausitzen sich gegenseitig als Ausland behandelten, musste beim Umzug von einem „sächsischen“ Landesteil in den anderen ein Abzugsgeld gezahlt werden, ganz so als wenn man das Kurfürstentum wirklich verlassen hätte. Ebenso durften die erbländischen Untertanen in den Nebenlanden - und umgekehrt - kein Rittergut erwerben oder einer Tätigkeit als Advokat nachgehen. ${ }^{33}$

Mit der bis 1806 noch vergleichsweise zurückhaltenden Kritik an der Landesverfassung rückte auch der Traditionsrezess offensichtlich noch nicht in den Blickpunkt der öffentlich-politischen Debatten. Und doch war er weiterhin präsent: Wie seine Vorgänger ersuchte auch Kurfürst Friedrich August III. bei seinem Regierungsantritt den Wiener Hof um die 1635 festgeschriebene Lehnserneuerung für die Lausitzen. ${ }^{34}$ Weiterer Handlungsbedarf ergab sich dann wenige Jahre später hinsichtlich der ebenfalls im Traditionsrezess festgehaltenen kirchlichen Schutz- und Oberaufsichtsrechte der Habsburger, die Sachsen bereits seit dem Westfälischen Frieden als ungerechtfertigte Einmischung in seine inneren Angelegenheiten empfand. Entsprechend versuchten die sächsischen Kurfürsten schon seit dem 17. Jahrhundert, den böhmischen Einfluss zurückzudrängen, ${ }^{35}$ und bezogen seit 1741 keine kaiserlichen Kommissare bei den Wahlen in den katholischen Stiftern mehr ein beziehungsweise ließen die Gewählten auch nicht mehr von den Habsburgern bestätigen. Dagegen setzte sich der Wiener Hof jedoch erfolgreich zur Wehr und erlangte 1773 von Friedrich August III. die Zusicherung, die Wahlen wieder nach den Vereinbarungen des Traditionsrezesses zu vollziehen. ${ }^{36}$

Dass Österreich seine lehnsherrlichen Rechte weiterhin ernst nahm, musste Sachsen wenig später im sogenannten Glauchauer Krieg erfahren, als Maria Theresia (reg. 1740-1780) zum Schutz ihrer böhmischen Reichsafterlehen Glauchau, Lichtenstein und Waldenburg aktiv in den sächsischen Konflikt mit den Schönburgern eingriff und 1777 Truppen nach Glauchau entsandte. ${ }^{37}$ Im Bayerischen

32 Vgl. Schmidt, Staatsreform in Sachsen (wie Anm. 23), S. 55 f.

33 Vgl. Sснміdт, Einschränkung der rechtlichen Sonderstellung (wie Anm. 2), S. 53.

34 Vgl. Thüмmel, Wem gehört die Oberlausitz (wie Anm. 1), S. 58.

35 Vgl. Pfeiffer, Verhältnis der Oberlausitz zur Krone Böhmen (wie Anm. 1), S. 81-86.

36 Vgl. ebd., S. 83.

$37 \mathrm{Zu}$ den Mediatisierungsbestrebungen der Wettiner gegenüber den Schönburgischen Herrschaften vgl. Michael Wetzel, Das schönburgische Amt Hartenstein 1702-1878. Sozialstruktur - Verwaltung - Wirtschaftsprofil (Schriften zur sächsischen Geschichte und Volkskunde 10), Leipzig 2004, hier insbesondere S. 150 f.; sowie WALTER SCHLESINGER, Die Landesherrschaft der Herren von Schönburg (Quellen und Studien zur Verfassungsgeschichte des Deutschen Reiches in Mittelalter und Neuzeit 9/1), Münster 1954, hier insbesondere S. 157 f. - Der Konflikt ist auch Teil der polnischen Dissertation: Jacek Kordel, Z Austrią czy z Prusami? Polityka zagraniczna Saksonii 1774-1778, 
Erbfolgekrieg unternahm Sachsen 1778/79 nochmals einen erfolglosen Versuch, die Habsburgermonarchie zum Verzicht auf ihre Rechte in den Lausitzen zu bewegen. ${ }^{38}$ Stattdessen übte der Wiener Hof seinen Einfluss auf die Kirchenverhältnisse sogar wieder verstärkt aus, ${ }^{39}$ während Sachsen für seine weitere ökonomische Entwicklung auf Österreich, das sich wie Preußen mit einer protektionistischen Politik gegen die Einfuhr sächsischer Waren wehrte und das ebenfalls als raubgieriger und unzuverlässiger Partner galt, ${ }^{40}$ politisch Rücksicht nehmen musste. Ein „hohe[s] Maß an Rechtssicherheit“ zu bieten, gehörte dabei zu den wichtigsten „wirtschaftspolitischen Maßnahmen, die ergriffen werden sollten, um den sächsischen Raum attraktiv zu machen". ${ }^{41}$ Auch dies ist sicherlich ein Grund, warum es zu keinen weiteren Verfassungsreformen kam, insbesondere zu keinen, die wie bei den Bestimmungen des Traditionsrezesses als ein Rechtsbruch hätten ausgelegt werden können.

\section{Reformbestrebungen wäbrend der napoleonischen Zeit 1806-1813}

Erst unter dem Druck Napoleons, ${ }^{42}$ der von seinem neuen Verbündeten Reformen nach französischem Vorbild erwartete, wurden in dem im Dezember 1806 zum Königreich erhobenen und in den Rheinbund aufgenommenen Sachsen Pläne für

Kraków 2018; der Autor plant die Veröffentlichung einer deutschsprachigen Zusammenfassung im Neuen Archiv für sächsische Geschichte.

38 Vgl. K[ARL] [W]ILHELm BöTTIGeR, Geschichte des Kurstaates und Königreiches Sachsen, Bd. 2: Von der Mitte des sechzehnten bis zu Anfang des neunzehnten Jahrhunderts (Geschichte der europäischen Staaten 6/1), bearbeitet von Th[eodor] Flathe, Gotha 21870 , S. 580.

39 Vgl. Lammel, Habsburg und die Oberlausitz (wie Anm. 2), S. 234.

40 So eine Flugschrift von 1806; hier zitiert nach Sammler, Territorialstaat oder Region (wie Anm. 29), S. 66.

41 Vgl. ebd., S. 57-60, Zitat = S. 59.

42 Zur napoleonischen Zeit in Sachsen vgl. mit weiterführenden Literaturverweisen: Stefan Gerber/Walter Rummel, Das Napoleonische Jahrzehnt: Mitteldeutschland/ Linksrheinisches Deutschland, in: Werner Freitag u. a. (Hg.), Handbuch Landesgeschichte, Berlin/Boston 2018, S. 166-198; Ulrike Höroldt/Sven Pabstmann (Hg.), 1815: Europäische Friedensordnung - Mitteldeutsche Neuordnung. Die Neuordnung auf dem Wiener Kongress und ihre Folgen für den mitteldeutschen Raum (Quellen und Forschungen zur Geschichte Sachsen-Anhalts 13), Halle 2017; Isabella Blank, Der bestrafte König? Die Sächsische Frage 1813-1815, Diss. Heidelberg 2013, online: archiv. ub.uni-heidelberg.de/volltextserver/15630/ [Zugriff: 12. August 2018]; Roman TöppeL, Die Sachsen und Napoleon. Ein Stimmungsbild 1806-1813 (Dresdner Historische Studien 8), Köln/Weimar/Wien 22013; WINFrIEd Müller, 1815 - Teilung statt Annexion. Von der napoleonischen Ära zum Wiener Kongress, in: Reinhardt Eigenwill (Hg.), Zäsuren sächsischer Geschichte, Beucha/Markkleeberg 2010, S. 136-152; Guntram Martin/Jochen Vötsch/Peter Wiegand (Hg.), 200 Jahre Königreich Sachsen. Beiträge zur sächsischen Geschichte im napoleonischen Zeitalter (Saxonia. Schriften des Vereins für sächsische Landesgeschichte 10), Beucha 2008. 
eine Landesunion erarbeitet. ${ }^{43}$ Die Modernisierungen in den benachbarten Rheinbundstaaten und in Preußen sowie die politischen und finanziellen Belastungen der napoleonischen Kriege ließen die Rückständigkeit der sächsischen Verfassung immer deutlicher zutage treten.

Die Forderungen nach einer grundlegenden Staatreform wurden daher immer lauter, und zwar angefangen beim sich emanzipierenden Bürgertum und den adligen Grundbesitzern über die tagtäglich mit den Problemen konfrontierten Verwaltungsbeamten bis hin zu den höchsten politischen Gremien des Landes. Doch Friedrich August I. hielt auch nach dem Wechsel an Napoleons Seite weiterhin zäh an der überholten sächsischen Verfassung fest. Statt nach süddeutschem Vorbild die neu gewonnene Souveränität als König zu nutzen und die verfassungsmäßigen Rechte der Stände zu beschränken, versicherte er ihnen 1807 auf dem ständischen Ausschusstag noch einmal ausdrücklich, an der Landesverfassung keine Veränderungen vorzunehmen. ${ }^{44}$ Auch die, vor dem Hintergrund der von anderen Rheinbundstaaten durchgeführten Säkularisationen und Mediatisierungen, nun diskutierte Inkorporierung der thüringischen Fürstentümer lehnte er - zumindest anfänglich $-\mathrm{ab} .{ }^{45}$

Trotz dieses retardierenden Einflusses des konservativen Königs gab es im Land deutliche Bestrebungen, endlich die notwendigen grundlegenden Reformen in Angriff zu nehmen. Anfänglich sah es sogar so aus, als würde es diesmal wirklich zu einem Ergebnis kommen: Die 1808 geschaffene „Kommission zur Wiederaufhelfung des Landes nach wiederhergestelltem Frieden“ wies in ihrem Abschlussbericht vom 12. März desselben Jahres erstmalig darauf hin, dass die notwendige Umsetzung einer Landesunion zwar schwierig, aber möglich wäre. Nur die Lausitzen und Henneberg hätten aufgrund ihrer besonderen Verfassungsverhältnisse wohl noch nicht inkorporiert werden können. Auch das Geheime Konsilium als Oberbehörde für alle Landesteile unterstützte nachdrücklich die empfohlene Schaffung eines einheitlichen Staates, besaß in Verfassungsfragen jedoch nur eine beratende Funktion. ${ }^{46}$ Gefällt wurden die Entscheidungen in der

43 Schmidt, Reformbestrebungen in Sachsen (wie Anm. 30), S. 3-58; Ders., Staatsreform in Sachsen (wie Anm. 23), S. 56-77; ReIner Gross, Reformbestrebungen in Kursachsen während der napoleonischen Zeit, in: Martin/Vötsch/Wiegand, 200 Jahre Königreich Sachsen (wie Anm. 42), Beucha 2008, S. 137-143, hier S. 140-143.

44 Vgl. Schмidt, Staatsreform in Sachsen (wie Anm. 23), S. $61 \mathrm{f}$.

45 Vgl. Sammler, Territorialstaat oder Region (wie Anm. 29), S. 67. Zur ablehnenden Haltung Friedrich Augusts I. gegenüber der Säkularisation bzw. Mediatisierung kleinerer Reichsstände, worauf aus seiner Sicht die Integration der thüringischen Staaten hinausgelaufen wäre, vgl. Petschel, Sächsische Außenpolitik (wie Anm. 27), S. 244-285. Peter Wiegand, Avantages compatibles avec la justice. Sachsens Gebietsansprüche zwischen Posen (1806) und Wien (1815), in: Höroldt/Pabstmann, Europäische Friedensordnung (wie Anm. 42), S. 63-95, hier S. 70-72, 88, zeigt hingegen, dass Friedrich August I. auch die thüringischen Staaten, mit Berufung auf alte Hausverträge und das Lehnrecht, als gerechtfertigte Entschädigungsmasse betrachtet hat.

$46 \mathrm{Zu}$ den Aufgaben und zum Einfluss der sächsischen Zentralbehörden vgl. ScHmidt, Staatsreform in Sachsen (wie Anm. 23), S. 49-54. 
eigentlichen Zentralbehörde, dem unmittelbar mit dem König zusammenarbeitenden Geheimen Kabinett. Und dort wurden die Reformvorschläge im Januar 1809, nach längerem Stillschweigen, rundum abgelehnt. ${ }^{47}$

Ob diese Ablehnung möglicherweise auch erfolgte, weil Friedrich August I. mit Blick auf das dem Rheinbund nicht beigetretene Österreich - zu diesem Zeitpunkt die in der Rheinbundakte verankerte Aufhebung aller fremden Hoheitsansprüche als rechtliche Voraussetzung für eine Landesunion noch zu unsicher war, muss hier offen bleiben. Jedenfalls erklärte der sächsische König im Spätsommer $1809^{48}$ auch für sein Land noch einmal ausdrücklich alle fremden Lehnsverhältnisse offiziell für erloschen, womit er auch die österreichischen Ansprüche an den Lausitzen negierte und den Weg für eine territoriale Vereinheitlichung ebnete. ${ }^{49}$ Auch Österreich vertrat zu diesem Zeitpunkt die Auffassung, dass kein Staat fremde Hoheitsrechte dulden müsse und hob die in Bayern, Württemberg und dem Fürstentum Reuß bestehenden böhmischen Lehnsbindungen auf. Ebenso wurde der böhmischen Landesverwaltung, die sich 1810 in der Oberlausitz in gewohnter Weise an einer geistlichen Wahl beteiligen wollte, „vom leitenden Minister in Wien [mitgeteilt], dass seit 1806 aus dem Traditionsrezess keine Befugnisse mehr herzuleiten seien." 50

Diese Einstellung des Wiener Hofes muss sich jedoch schnell wieder gedreht haben, wie sich in der Folge des sächsischen Landtags von 1811 zeigte. Gerade von diesem Landtag51 erhofften sich die sächsischen Reformkräfte endlich Verfassungsänderungen nach dem Vorbild der anderen Rheinbundstaaten. Wichtigster Diskussionspunkt war der durch die napoleonischen Kriegszüge erhöhte Finanzbedarf, den die erbländischen Stände ${ }^{52}$ der Ritterschaft und Städte stärker auf die Nebenlande verteilt sehen wollten, weshalb sie - ebenso wie das Geheime Finanzkollegium - die Vereinigung aller Landesteile beantragten. Gegen diesen Vorschlag sprach sich jedoch die einflussreiche erste Landtagskurie der Prälaten, Grafen und Herren aus, die befürchteten, ihre weitreichenden Sonderrechte in den Nebenländern würden damit auf den Stand der Erbländer reduziert werden. Diese beiden

47 Vgl. Schmidt, Reformbestrebungen in Sachsen (wie Anm. 30), S. 4 f.; Ders., Staatsreform in Sachsen (wie Anm. 23), S. $63 \mathrm{f}$.

48 Vgl. Wiegand, Sachsens Gebietsansprüche (wie Anm. 45), S. 81.

49 Vgl. Sammler, Territorialstaat oder Region (wie Anm. 29), S. 67.

50 Thüмmes, Wem gehört die Oberlausitz (wie Anm. 1), S. 56.

51 Vgl. Rudolf MeYer, Der sächsische Landtag von 1811 (Bibliothek der sächsischen Geschichte und Landeskunde 3/2), Leipzig 1912; SCHмIDT, Reformbestrebungen in Sachsen (wie Anm. 30), S. 5-18; Ders., Staatsreform in Sachsen (wie Anm. 23), S. 64-68; Gross, Reformbestrebungen in Kursachsen (wie Anm. 43), S. 140-143; Schwanitz, Die Idee der „natürlichen Grenzen“ (wie Anm. 29).

$52 \mathrm{Zu}$ den sächsischen Ständen vgl. den zuletzt erschienenen Überblick von Uwe Schirmer: Sabine Holtz/Uwe Schirmer, Landstände und Parlamentarismus: Württemberg / Sachsen und Thüringen, in: Freitag, Handbuch Landesgeschichte (wie Anm. 42), S. 335369, hier S. 351-361; sowie die einschlägigen Arbeiten von Josef Matzerath, insbesondere in der von ihm herausgegebenen Reihe „Aspekte sächsischer Landtagsgeschichte.“ 
unterschiedlichen Meinungen zeigten sich nicht nur auf dem Landtag selbst, sondern auch innerhalb der Behörden, bis hinein in das Geheime Kabinett.

Hatten die hinsichtlich einer territorialen Vereinheitlichung geführten politischen Debatten bislang noch keinen größeren publizistischen Niederschlag erfahren, gipfelten sie diesmal ebenfalls in einer Vielzahl von Denkschriften. ${ }^{53}$ Darin wurden aus unterschiedlichsten Perspektiven nicht nur die Vor- oder Nachteile, sondern bereits auch die rechtliche Legitimität der Unionspläne äußerst kontrovers diskutiert. Bezüglich der Lausitzen findet sich eine große Bandbreite der Meinungen, die von der weiteren Gültigkeit und damit noch nicht möglichen Eingliederung bis hin zum völligen Erlöschen des Traditionsrezesses reicht.

Im Geheimen Konsilium - als einem „Zentrum der Reformbestrebungen“54 _ überwogen beispielsweise eindeutig die Vorteile einer Landesunion. Die Geheimen Räte wiesen Friedrich August I. daher schon frühzeitig darauf hin, dass ihrer Auffassung nach die Vereinigung aller Landesteile keine Zustimmung der Provinzialstände bedürfe, sondern bereits durch eine königliche Entscheidung herbeigeführt werden könne. Allein die Lausitzen stellten hierbei eine Ausnahme dar, da sich die Vereinbarung des Prager Haupt-und Traditionsrezesses von 1635 auf ein nicht zum Deutschen Reich gerechnetes Zubehör der Krone Böhmen bezog. ${ }^{55}$ Hier hielt das Geheime Konsilium daher zuvor eine besondere Übereinkunft mit Österreich erforderlich. Interessanterweise standen selbst die Provinzialstände der Ober- und Niederlausitz dem Unionsgedanken durchaus zustimmend gegenüber, da sie sich hiervon - bei weitestgehender Aufrechterhaltung ihrer Sonderrechte steuerliche Vorteile versprachen. ${ }^{56}$

Im Geheimen Kabinett herrschten zwar weiterhin geteilte Auffassungen, doch als Friedrich August I. im März 1811, entgegen seiner persönlichen Überzeugung, ${ }^{57}$ der Einschätzung der befürwortenden Partei folgte und der Union zustimmte, um nicht das Verhältnis zu Napoleon zu belasten, schien die langersehnte Verfassungsreform in greifbare Nähe gerückt. Als dann das Geheime Konsilium ganz konkret mit der Erarbeitung eines ersten Verfassungsentwurfs beauftragt wurde, waren die Unionspläne so weit gediehen, dass erstmals seit fast vier Jahrzehnten Österreich wieder intervenierte und unter Berufung auf den Traditionsrezess Einspruch gegen die geplante Inkorporation der Lausitzen erhob. ${ }^{58}$ Vom Wiener Standpunkt aus nahmen das Ende des Alten Reichs und die Gründung des Rheinbunds keinen Einfluss auf das böhmische Lehnsverhältnis der Lausitzen. Dass

53 Eine ausführliche Analyse dieser politischen Denkschriften bieten: ScHMIDT, Reformbestrebungen in Sachsen (wie Anm. 30), S. 22-58; Ders., Staatsreform in Sachsen (wie Anm. 23), S. 65-77.

54 Schmidt, Staatsreform in Sachsen (wie Anm. 23), S. 69.

55 Zitiert nach der paraphrasierenden Darstellung bei Sснміdт, Reformbestrebungen in Sachsen (wie Anm. 30), S. 11; vgl. auch Meyer, Der sächsische Landtag von 1811 (wie Anm. 51), S. 69.

56 Vgl. Schmidt, Einschränkung der rechtlichen Sonderstellung (wie Anm. 2), S. 55.

57 Vgl. Schmid, Staatsreform in Sachsen (wie Anm. 23), S. 66.

58 Vgl. Schмid, Reformbestrebungen in Sachsen (wie Anm. 30), S. 18. 
selbst höchste sächsische Behörden diese Auffassung teilten, verdeutlicht das bereits angeführte Beispiel des Geheimen Konsiliums. Verständlicherweise wollte beziehungsweise konnte sich die sächsische Regierung dieser Meinung nicht anschließen, da sie ja dem eigenen Souveränitätsanspruch entgegen lief. Mit dem Argument, dass auch Österreich die Rheinbundakte anerkannt habe, sah man die alten Lehnsansprüche als endgültig erloschen an.

Letztendlich musste diese Frage aber nicht mehr abschließend geklärt werden. Mit dem weiteren militärischen Verlauf der napoleonischen Kriege war auch die politische Umsetzung der Landesunion obsolet geworden. Als französischer Verbündeter war das Königreich Sachsen seit dem im Sommer 1812 begonnenen Russlandfeldzug so hohen militärischen und finanziellen Belastungen ausgesetzt, dass grundlegende Verfassungsänderungen nicht mehr umsetzbar waren, insbesondere nicht gegen den immer noch vorhandenen innenpolitischen Widerstand. 59 Sachsen verpasste damit zwar seine erste große Chance auf wirkliche Verfassungsreformen, trotzdem war der seit 1808 geführte politische Diskurs aber ein wichtiger Schritt auf dem Weg zum Einheitsstaat. Die Probleme und Möglichkeiten der Staatsreform waren laut Gerhard Schmidt bereits soweit diskutiert und geklärt, dass sie letztlich die in den 1830er-Jahren erreichte Einheit des sächsischen Staates vorbereiteten. 60

\section{Besatzungs- und Restaurationszeit 1813-1827}

Friedrich August I. - der das Bündnis mit Napoleon wohl „von Anfang an“ als Möglichkeit begriff, zulasten Preußens wieder die alte sächsische Vormachtstellung in Mitteldeutschland zurückzuerlangen und der dieses Ziel selbst nach der vernichtenden Leipziger Völkerschlacht im Oktober 1813 nicht aus den Augen verlor 61 - musste für seine Haltung bekanntermaßen einen hohen Preis zahlen. Von den in Leipzig einrückenden Siegern als Kriegsgefangener betrachtet und in preußische Gefangenschaft verbracht, konnte er keinen Einfluss mehr darauf nehmen, dass sein Land erst unter die Verwaltung eines russischen und dann im November 1814 preußischen Generalgouvernements ${ }^{62}$ gestellt wurde.

Mit der uneffektiven sächsischen Verwaltung konfrontiert bemühte sich die neue oberste Besatzungsbehörde recht schnell um Reformen.63 Die dabei auch in Betracht gezogenen Pläne für eine Landesunion gingen hinsichtlich der Lausitzen sogar noch weiter als die vorherigen sächsischen Überlegungen. So wollte das russische Generalgouvernement beispielsweise noch im Verlauf des Jahres 1813 die

59 Vgl. Sснмідт, Einschränkung der rechtlichen Sonderstellung (wie Anm. 2), S. 56, 72.

60 Vgl. Schмidt, Reformbestrebungen in Sachsen (wie Anm. 30), S. 22.

61 Vgl. Wiegand, Sachsens Gebietsansprüche (wie Anm. 45), S. 91.

62 Vgl. Blank, Der bestrafte König (wie Anm. 42), S. 147-152.

63 Vgl. ebd., S. 151 f.; SснміDт, Reformbestrebungen in Sachsen (wie Anm. 30), S. 20-22. 
Sonderverfassungen der Lausitzen vollständig beseitigen. ${ }^{64} 1814$ wurde dann zwar noch unter russischer Verwaltung die bisherige Zahlung eines Abzugsgeldes innerhalb der sächsischen Landesteile aufgehoben, ${ }^{65}$ letztendlich verliefen die Unionspläne aber erneut im Sande. Denn einerseits fühlten sich die sächsischen Behörden während der Abwesenheit ihres Königs nicht zu so tiefgreifenden Änderungen befugt, und andererseits argumentierte auch Preußen, dass einer provisorischen Regierung solche Aufgaben nicht oblägen. Hintergrund der preußischen Ablehnung war jedoch vielmehr die angestrebte vollständige Eingliederung Sachsens in den preußischen Staat, mit den dann sowieso notwendigen administrativen und strukturellen Anpassungen an die eigenen Verfassungsverhältnisse. ${ }^{66}$

Auf dem Wiener Kongress ${ }^{67}$ konnten Frankreich und Österreich, die ihre eigenen machtpolitischen Interessen gefährdet sahen, die vollständige Annektierung Sachsens zwar verhindern, trotzdem musste sich Friedrich August I. aber mit dem Verlust von ca. zwei Dritteln seines Territoriums - in denen über 40 Prozent seiner Einwohner lebten und fast 50 Prozent der Steuerzahlungen herkamen - abfinden.68 Für Sachsen bedeutete dies unter anderem den Verlust der gesamten Niederlausitz sowie des größten Teils der Oberlausitz. Auch der bei Sachsen verbliebene Teil der Oberlausitz, auf den sich die folgenden Ausführungen beschränken, wurde von der Teilung hart getroffen. ${ }^{69}$ Beinahe der gesamte Görlitzer und große Teile des Bautzener Kreises mussten abgetreten werden, darunter das Kloster Lauban, die Standesherrschaften Hoyerswerda und Muskau sowie Teile des Grundbesitzes des Klosters Marienstern. Mit dem Verlust der Städte Görlitz und Lauban war von dem einstmals politisch so einflussreichen Sechsstädtebund nur noch ein

64 Vgl. Schмidt, Einschränkung der rechtlichen Sonderstellung (wie Anm. 2), S. 55, Anm. 7.

65 Vgl. Schmidt, Staatsreform in Sachsen (wie Anm. 23), S. 56.

66 Vgl. Blank, Der bestrafte König (wie Anm. 42), S. 151 f.

67 Zur „Sächsischen Frage“ auf dem Wiener Kongress vgl. ebd., S. 169-271.

68 Vgl. Rudolf Jenak, Die Teilung Sachsens. Zur Geschichte der Teilung des Königreiches Sachsen auf der Grundlage der Entscheidungen des Wiener Kongresses 1814-1815, Dresden 2007; zur praktischen Umsetzung der sich bis September 1819 hinziehenden Landesteilung vgl. Blank, Der bestrafte König (wie Anm. 42), S. 274-279.

$69 \mathrm{Zu}$ den an Preußen abgetretenen oberlausitzischen Landesteilen vgl. LeszeK BeLzYT/ Hans-Werner Rautenberg, Die Oberlausitz vom Wiener Kongreß bis zum Ende des Ersten Weltkriegs (1815-1918), in: Joachim Bahlcke (Hg.), Geschichte der Oberlausitz. Herrschaft, Gesellschaft und Kultur vom Mittelalter bis zum Ende des 20. Jahrhunderts, Leipzig 2001, S. 181-220, hier S. 181-184; sowie Karlheinz Blaschke, Bewahrte Einheit. Die Oberlausitz in den 130 Jahren erzwungener Teilung 1815-1945, in: Sammeln - Erforschen - Bewahren. Zur Geschichte und Kultur der Oberlausitz (Neues Lausitzisches Magazin, Sonderheft), hrsg. von der Oberlausitzischen Gesellschaft der Wissenschaften zu Görlitz e. V., Hoyerswerda/Görlitz 1999, S. 264-292. - Eine Kartendarstellung bietet: MoschKe, Geschichte der Oberlausitzer Ständeversammlung (wie Anm. 19), S. 22 f. 
schwacher und mit der Teilung seiner Existenzberechtigung beraubter Vierstädtebund übrig geblieben. ${ }^{70}$

Als im Juni 1815 Friedrich August I. in sein stark verkleinertes und vom zurückliegenden Krieg nicht nur wirtschaftlich schwer gezeichnetes Land zurückkehrte, stand somit als eine der dringendsten Aufgaben eine Verfassungs- und Verwaltungsreform des Restgebietes an. ${ }^{71}$ Noch im selben Monat kündigte daher das Geheime Kabinett an, im Zuge der nun gebotenen Einsparungen auch den viel $\mathrm{zu}$ umfangreichen und umständlichen Behördenapparat zu modernisieren. Zur Optimierung der Verwaltung sollten nun auch die verbliebenen Nebenländer vollständig in die Erblande eingegliedert und die bisherigen Provinzial- den Dresdner Zentralbehörden unterstellt werden. Für die Oberlausitz hätte dies auch den Verlust der ständischen Sonderrechte bedeutet, was folgerichtig auf Veränderungen an der althergebrachten Kirchenverfassung sowie auf eine Angleichung des Steuerund Schuldenwesens hinausgelaufen wäre.

Als diesmal die Oberlausitzer Stände, anders noch als 1811, daher „schärfsten Widerstand“ leisteten, ${ }^{72}$ führte die Eingliederungsfrage erneut zu heftigen Diskussionen in den Dresdner Zentralbehörden. Selbst im Geheimen Kabinett wurde dabei unter anderem die Auffassung geäußert, dass die Eingliederung der Oberlausitz staatsrechtlich weder legitim noch notwendig sei. ${ }^{73}$ Auch der König und sein ebenso konservativer Kabinettsminister Detlef Graf von Einsiedel (1773$1861)^{74}$ vertraten die Auffassung, Verfassungsänderungen würden die Verwirrungen im Lande nur unnötig steigern und sprachen sich daher im Juli 1817 gegen eine vollständige Inkorporierung aus. Eine nicht unwesentliche Rolle spielte hierbei auch das Bestreben, das außenpolitische Verhältnis zu Wien nicht zu belasten. ${ }^{75}$ Gerade mit Blick auf die preußischen Annexionswünsche sollte der so wichtige österreichische Rückhalt nicht aufs Spiel gesetzt werden, war doch absehbar, dass der Wiener Hof wie schon 1811 gegen die Integration der Oberlausitz protestieren würde. Zusätzlich hemmte die sich immer stärker abzeichnende Konkurrenz zwischen den beiden wichtigsten Zentralbehörden - dem für das im Oktober 1817 aufgelöste Geheime Konsilium neu begründeten Geheimen Rat mit seiner nun-

70 Vgl. Swen Steinberg, Die Oberlausitz von 1815 bis in die Gegenwart, in: Müller, Oberlausitz (wie Anm. 7), S. 97-140, hier S. 101; allgemein zum Sechsstädtebund vgl. z. B. Tino Fröde, Privilegien und Statuten der Oberlausitzer Sechsstädte. Ein Streifzug durch die Organisation des städtischen Lebens in Zittau, Bautzen, Görlitz, Löbau, Kamenz und Lauban in der frühen Neuzeit, Spitzkunnersdorf 2008.

71 Vgl. Schmidt, Reformbestrebungen in Sachsen (wie Anm. 30), S. 59-115; Ders., Staatsreform in Sachsen (wie Anm. 23), S. 78-93; DERs., Einschränkung der rechtlichen Sonderstellung (wie Anm. 2), S. 58-67.

72 Vgl. Schmidt, Einschränkung der rechtlichen Sonderstellung (wie Anm. 2), S. 55, Anm. 7.

73 Vgl. ebd., S. 62 f.

74 Vgl. Michael Wetzel, Einsiedel, Detlev Graf von, in: Sächsische Biografie, herausgegeben vom Institut für Sächsische Geschichte und Volkskunde, online: saebi.isgv.de [Zugriff: 12. August 2018].

75 Vgl. Scнміdт, Einschränkung der rechtlichen Sonderstellung (wie Anm. 2), S. 67. 
mehr fast nur noch beratenden Funktion und dem somit politisch noch weiter aufgewerteten Geheimen Kabinett als der sächsischen Zentralbehörde ${ }^{76}$ - die Eingliederung der Oberlausitz.

So kam es zwar, trotz des ständischen Widerstandes, nach 1815 auch bei den Oberlausitzer Behörden zu halbherzigen, „auf das Maß des Unerlässlichen beschränkt[en]" Veränderungen, ${ }^{77}$ die Verfassung selbst fand jedoch nur in einzelnen Punkten eine Annäherung an die sächsischen Verhältnisse. Hervorzuheben ist hierbei, dass seit 1817 auch die Oberlausitzer Stände - wiederum „nicht ganz ohne ihre Gegenwehr“ - mit zu den allgemeinen sächsischen Landtagen herangezogen wurden und somit an der politischen Entscheidungsfindung für ganz Sachsen beteiligt waren. ${ }^{78}$ Am weiteren Bestand der oberlausitzischen Provinzialversammlung wurde damit aber nicht gerüttelt. Insgesamt gesehen blieb Sachsen weiterhin bei seinen veralteten und überholten Verfassungsverhältnissen und fiel damit „von 1815 bis 1835 in seiner staatlichen Entwicklung noch mehr als vorher hinter anderen Ländern zurück“.79

\section{Auf dem Weg zum konstitutionellen Einheitsstaat 1827-1835}

Die verpassten Verfassungsreformen ließen in Sachsen die bestehende Kluft zwischen dem hohen wirtschaftlichen und kulturellen Entwicklungsstand auf der einen und der politischen Rückständigkeit auf der anderen Seite immer deutlicher zutage treten. Doch auch der Regierungswechsel 1827 brachte nicht die erhoffte

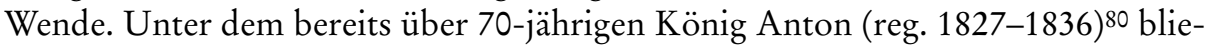
ben „Stagnation und Behinderung allen politischen Fortschritts“ die bestimmende Regierungsweise. ${ }^{81}$ Entsprechend wuchs die Unzufriedenheit und Opposition im Lande, was sich im September 1830 in gewaltsamen Unruhen entlud. ${ }^{82}$ Nun endlich wurde von der neu eingesetzten Regierung unter dem liberalen Kabinetts-

76 Vgl. Schmidt, Reformbestrebungen in Sachsen (wie Anm. 30), S. 75-93; Ders., Staatsreform in Sachsen (wie Anm. 23), S. 84 f.

77 Schмid, Einschränkung der rechtlichen Sonderstellung (wie Anm. 2), S. 57.

78 Vgl. Josef Matzerath, Die Eingliederung der Oberlausitzer in die sächsische Ständeversammlung, in: Sammeln - Erforschen - Bewahren (wie Anm. 69), S. 293-302, Zitat = S. 293.

79 Schmidt, Einschränkung der rechtlichen Sonderstellung (wie Anm. 2), S. 57.

80 Vgl. Wolfgang Tischner, Anton 1827-1836, in: Kroll, Die Herrscher Sachsens (wie Anm. 6), S. 223-236, 343 f.

81 Schmid, Einschränkung der rechtlichen Sonderstellung (wie Anm. 2), S. 68.

82 Vgl. Michael Hammer, Volksbewegung und Obrigkeiten. Revolution in Sachsen 1830/31 (Geschichte und Politik in Sachsen 3), Weimar/Köln/Wien 1997; Siegfried Schмidt, Die Entwicklung der politischen Opposition im Königreich Sachsen zwischen 1830 und 1848 (Bausteine aus dem Institut für Sächsische Geschichte und Volkskunde 2), Dresden 2005. 
Frank Metasch

minister Bernhard August von Lindenau (1779-1854)83 die lange überfällige, umfassende Reform der Landesverfassung angekündigt. Ein Jahr später, am 4. September 1831, trat als Kernstück und Fundament des gesamten folgenden Reformwerks ${ }^{84}$ die neue schriftliche Verfassung 85 in Kraft.

Gleich im ersten Abschnitt der Verfassungsurkunde wurde die neue Einheit des gesamten Staatsterritoriums betont: Das Königreich Sachsen ist ein unter Einer Verfassung vereinigter, untheilbarer Staat des deutschen Bundes. Um diese postulierte Staatseinheit zu verwirklichen, sollten endlich auch die verbliebenen Nebenländer in den Gesamtstaat integriert und ihre Sonderrechte aufgehoben werden. Doch gerade die Eingliederung der Oberlausitz stellte sich weiterhin als schwierige Aufgabe dar. ${ }^{86}$

Durch ihre Einbindung in die sächsische Ständeversammlung waren auch die Oberlausitzer Stände an den Beratungen zur neuen sächsischen Verfassung beteiligt, und verständlicherweise wehrten sie sich gegen den drohenden Verlust ihrer althergebrachten Sonderrechte - vor allem da ihnen König Anton am 19. Oktober 1827 bei seinem Regierungsantritt ausdrücklich noch einmal die Gültigkeit der dem Traditionsrecesse vom Jahre 1635 nicht zuwiderlaufende[n] Privilegien schriftlich bestätigt hatte. ${ }^{87}$ Auch in den Verfassungsberatungen ging die sächsische Regierung von der Prämisse aus, dass mit Rücksicht auf den Traditionsrezess die neue Verfassung nicht einfach per Gesetz auf die Oberlausitz übertragen werden könne, sondern zuvor die Zustimmung der dortigen Provinzialstände eingeholt werden müsse. ${ }^{88}$

Die sächsische Verfassung vom 4. September 1831 erhielt daher in der Oberlausitz nicht automatisch ihre volle Gültigkeit. Erst einmal musste die sächsische Regierung mit den Provinzialständen über die notwendigen Anpassungen verhandeln. ${ }^{89}$ Bis zur abschließenden Regelung wurde den Oberlausitzer Ständen versichert, dass sie an die gesamtsächsische Verfassung nur soweit gebunden seien, wie diese ihre auf dem Traditionsrezess beruhenden Privilegien nicht verletze. Diese von König Anton gegebene Zusicherung spiegelte allerdings nur die Auffassung eines Teils der Ersten Kammer des Sächsischen Landtags wider. Die Zweite

83 Vgl. Oliver Werner, Lindenau, Bernhard von, in: Sächsische Biografie (wie Anm. 74).

84 Immer noch grundlegend: SchмidT, Staatsreform in Sachsen (wie Anm. 23).

85 Mit einer Edition des Verfassungstextes: Christoph Jestaedt, Die Sächsische Verfassung von 1831, in: Thomas Pfeiffer (Hg.), Sachsen als Verfassungsstaat, Berlin 1998, S. 11-43, 141-153.

86 Vgl. Schmid, Staatsreform in Sachsen (wie Anm. 23), S. 178-187; Ders., Einschränkung der rechtlichen Sonderstellung (wie Anm. 2), S. 68-83; sowie die darauf basierende Zusammenfassung bei Belzyt/Rautenberg, Oberlausitz (wie Anm. 69), S. 187-195.

87 Zitiert nach Deumer, Rechtlicher Anspruch Böhmen-Österreichs (wie Anm. 1), S. 32 f.; vgl. auch Thüмmel, Wem gehört die Oberlausitz (wie Anm. 1), S. 60.

88 SсHмidт, Einschränkung der rechtlichen Sonderstellung (wie Anm. 2), S. 68; Deumer, Rechtlicher Anspruch Böhmen-Österreichs (wie Anm. 1), S. 34.

89 Vgl. Max Herzog zu Sachsen, Staatsrechtliche Stellung des Markgraftums Oberlausitz (wie Anm. 1), S. 22 f.; Deumer, Rechtlicher Anspruch Böhmen-Österreichs (wie Anm. 1), S. 33 f. 
Kammer vertrat stattdessen die Ansicht, die neue Verfassung gelte bereits im vollen Umfang auch für die Oberlausitz. ${ }^{90}$

Ergebnis der langwierigen Verhandlungen war eine am 17. November 1834 speziell für die Oberlausitz verabschiedete Verfassungsurkunde. ${ }^{91}$ Diese neue Particular-Verfassung ${ }^{92}$ regelte nicht nur die Integration der Oberlausitz in den sächsischen Gesamtstaat, sie wurde wie zuvor der Traditionsrezess zu einem „Zweiten Staatsgrundgesetz“93 des Königreichs Sachsen. Denn die sächsischen Könige sollten bei ihrem Regierungsantritt zukünftig nicht mehr nur das Versprechen geben, die sächsische Verfassung vom 4. September 1831, sondern auch die Oberlausitzer Partikularverfassung vom 17. November 1834 aufrechtzuerhalten und zu schützen. ${ }^{94}$ Für die Oberlausitz besaß die Urkunde von 1834 aus staatsrechtlicher Sicht sogar eine „größere Kraft“ als die gesamtsächsische Verfassung, da in den Fällen, wo beide in Konflikt geraten wären, die Partikularverfassung den Vorrang besaß. Im Gegensatz zur sächsischen Gesamtverfassung durften an der oberlausitzischen Partikularverfassung selbst mittels eines verfassungsändernden Gesetzes keine Änderungen vorgenommen werden, sofern nicht zuvor die Zustimmung der dortigen Provinzialstände eingeholt worden wäre. ${ }^{95}$

Den abschließenden Schritt bei der Einbindung der Oberlausitz bildete die königliche Verordnung vom 24. Januar 1835 Über die Gleichstellung der Kreislande und der Oberlausitz, soweit sie bisher gegen einander als Ausland betrachtet worden sind.$^{96}$ Erst ab diesem Datum galt die Oberlausitz, dem Wortlaut der Verordnung gemäß, den sächsischen Behörden offiziell nicht mehr als Ausland, sondern in allen Belangen als ein Teil des sächsischen Inlandes. Auch wenn sich diese

90 Vgl. Max Herzog zu Sachsen, Staatsrechtliche Stellung des Markgraftums Oberlausitz (wie Anm. 1), S. 23, Anm. 1.

91 Zur Urkunde, die durch Anwendung der Verfassung des Königreiches Sachsen auf die Oberlausitz bedingte Modification der Particular-Verfassung dieser Provinz betreffend, vgl. Max Herzog zu Sachsen, Staatsrechtliche Stellung des Markgraftums Oberlausitz (wie Anm. 1), S. 27-39; Deumer, Rechtlicher Anspruch Böhmen-Österreichs (wie Anm. 1), S. 31-59. Publiziert wurde die Urkunde in: Sammlung der Gesetze und Verordnungen für das Königreich Sachsen vom Jahre 1834, Dresden o. J., S. 482-539.

92 Die Urkunde vom 17. November 1834 regelte die neuen Verhältnisse allerdings nicht selbst, sondern verwies dafür an das auf denselben Tag datierende Provinzialständische Statut. Beide, Urkunde und Provinzialstatut, bilden somit zusammen die Provinzialverfassung; zum Provinzialstatut vgl. Max Herzog zu SACHSEN, Staatsrechtliche Stellung des Markgraftums Oberlausitz (wie Anm. 1), S. 40-45; Schmidt, Einschränkung der rechtlichen Sonderstellung (wie Anm. 2), S. 77.

93 Max Herzog zu Sachsen, Staatsrechtliche Stellung des Markgraftums Oberlausitz (wie Anm. 1), S. 39.

94 Vgl. Deumer, Rechtlicher Anspruch Böhmen-Österreichs (wie Anm. 1), S. 36; Max Herzog zu Sachsen, Staatsrechtliche Stellung des Markgraftums Oberlausitz (wie Anm. 1), S. $38 \mathrm{f}$.

95 Vgl. Max Herzog zu Sachsen, Staatsrechtliche Stellung des Markgraftums Oberlausitz (wie Anm. 1), S. 28.

96 Publiziert in: Gesetz und Verordnungsblatt für das Königreich Sachsen vom Jahre 1835, Dresden o. J., S. 50 f. 
Angleichung nur noch auf wenige Ressorts, wie zum Beispiel Vormunds- und Lehnsangelegenheiten bezog, bestätigte die sächsische Regierung damit letztendlich noch einmal, dass die Oberlausitz bislang kein integraler Bestandteil des sächsischen Staatsgebietes, sondern mit diesem nur in Personalunion verbunden war. ${ }^{97}$

Die Partikularverfassung vom 17. November 1834 regelte zwar einerseits erstmalig die vollständige Integration der Oberlausitz in das Königreich Sachsen, garantierte ihr andererseits aber weiterhin ihre verfassungsmäßige Sonderstellung. Dieser in der Partikularverfassung formulierte Sonderstatus fußte wiederum auf dem Traditionsrezess von 1635. Allerdings galten laut Paragraf 1 nun alle Sonderrechte nur noch in der Form, wie sie in der Urkunde aufgenommen waren. Alle nicht mehr erwähnten Privilegien waren somit ungültig, und nicht mehr erwähnt wurden eben vor allem die lehnsrechtliche Bindung an die Habsburger sowie deren kirchlichen Oberaufsichtsrechte. Bezeichnenderweise wollte die sächsische Regierung aber diese Punkte offensichtlich auch nicht expressis verbis als erloschen erklären. Stattdessen wurde in Paragraf 60 sogar noch ausdrücklich festgehalten, dass die Partikularverfassung nur solange gelte, wie die Oberlausitz mit der sächsischen Verfassung vom 4. September 1831 verbunden sei. Sofern die Oberlausitz an dieser Verfassung nicht mebr Theil nehmen könnte, sollte die bisherige, auf den Tradi-tionsrece $\beta$ vom 30sten Mai 1635., den Traditionsabschied vom 24sten April 1636. und sonst gegründete Verfassung der Provinz von selbst wieder ibre Kraft [erlangen] und [...] obne Weiteres in Wirksamkeit [treten]. Selbst die nicht mehr in der Partikularverfassung enthaltenen Bestimmungen des Traditionsrezesses waren somit nur auf Widerruf erloschen.

Eine solche Loslösung von der sächsischen Verfassung hätte - laut der Dissertation von Max Herzog zu Sachsen ${ }^{98}$ - eigentlich nur beim Aussterben der männlichen Linie der regierenden Albertiner eintreten können. In diesem Fall hätten in der Oberlausitz nicht die in Paragraf 7 der sächsischen Verfassung enthaltenen Bestimmungen zur Thronfolge Anwendung gefunden, sondern die alten Sukzessionsbestimmungen des Traditionsrezesses wären automatisch wieder in Kraft getreten, und zwar bis hin zum möglichen Heimfallrecht an Böhmen.

Dass die Oberlausitz also auch weiterhin eine - letztlich noch immer auf dem Traditionsrezess fußende - verfassungsmäßige Sonderstellung genoss, zeigte sich schon besonders symbolträchtig im Fortbestehen der mit weitreichenden Rechten versehenen Oberlausitzer Ständeversammlung. Entgegen der in der landesgeschichtlichen Forschung vorherrschenden Meinung, alle sächsischen Gesetze wären spätestens seit 1834 automatisch in der Oberlausitz gültig gewesen, besaßen die dortigen Provinzialstände selbst im Bereich der Gesetzgebung noch ein Mitwirkungsrecht. Gemäß Paragraf 3 der Partikularurkunde konnten die sächsischen Gesetze erst nach erfolgter Beratung und Zustimmung der oberlausitzischen Stän-

97 Vgl. Deumer, Rechtlicher Anspruch Böhmen-Österreichs (wie Anm. 1), S. 44; Schmidt, Einschränkung der rechtlichen Sonderstellung (wie Anm. 2), S. 70.

98 Vgl. Max Herzog zu Sachsen, Staatsrechtliche Stellung des Markgraftums Oberlausitz (wie Anm. 1), S. 28 f. 
deversammlung in der Oberlausitz [...] publiziert werden. ${ }^{99}$ Noch 1884 wies Heinrich Deumer in seiner staatsrechtlichen Betrachtung darauf hin, dass auch weiterhin die Möglichkeit bestände, dass die Oberlausitz einem sächsischen Gesetz ihre Zustimmung verwehre und dass „in einem solchen Falle der Regierung [...] nichts Anderes übrig [bliebe] als dem Wunsche der Stände des Markgrafthums Oberlausitz [...] nachzugeben." 100 Dass dieser Fall nie eingetreten ist, lag wohl vor allem daran, dass die Oberlausitzer Stände über ihre Integration in den Sächsischen Landtag schon zuvor an den gesetzbildenden Prozessen beteiligt waren und ihre Bedenken somit bereits dort vorbringen konnten. Mehrfach mussten die gesamtsächsischen Gesetze daher - wie im Folgenden noch gezeigt wird - auf die Oberlausitz Rücksicht nehmen und konnten zum Teil dort keine Gültigkeit erlangen.

Ebenso weitreichend waren die Sonderregelungen hinsichtlich der Oberlausitzer Religions- und Kirchenverfassung, ${ }^{101}$ die ebenfalls weiterhin ausdrücklich auf den Bestimmungen von 1635 basierten. Um dieses Zugeständnis - das der sächsischen Regierung auch zukünftig die Möglichkeit nahm, eine einheitliche sächsische Kirchenordnung einzuführen - durchzusetzen, hatten die Klostervögte von Marienstern und Marienthal anfänglich sogar ihren Eid auf die Verfassung verweigert. ${ }^{102}$ Konkret heißt es auch hier in der Partikularurkunde, Paragraf 3: Der Oberlausitz wird hiermit zugesagt, daß in ibrer Religions- und kirchlichen Verfassung, welche durch den Traditonsrece $\beta$ [...] und den Traditonsabschied [...] vertragsmäßig feststeht, obne vorheriges ausdrücklich erklärtes Einverständniß der oberlausitzer Provinzialstände nichts geändert werden solle. ${ }^{103}$

Da in der Oberlausitz durch den prager Vertrag von 1534. und sonst eine größere Freibeit des Gewerbes [bestand], als in den Erblanden, durfte laut Paragraf 5 auch in die Gewerbeverhältnisse nicht eingegriffen werden. Explizit wurden die Gewerbekonzessionen genannt, die in der Oberlausitz - außerhalb einer Bannmeile um die Sechs- beziehungsweise nunmehr Vierstädte - jeder Guts- und Grundherr sowie jeder Stadtrat auf seinen Besitzungen in beliebiger Anzahl erteilen durfte. An dieser „einmalig weiten Gewerbefreiheit“ 104 durfte nur gegen eine, mit Zustimmung der Provinzialstände für angemessen zu achtende Entschädigung

99 Gesetze und Verordnungen 1834 (wie Anm. 91), S. 483 f.; vgl. auch Schmidt, Einschränkung der rechtlichen Sonderstellung (wie Anm. 2), S. 76 f.; DERs., Staatsreform in Sachsen (wie Anm. 23), S. 180.

$100 \mathrm{Vgl}$. Deumer, Rechtlicher Anspruch Böhmen-Österreichs (wie Anm. 1), S. 41 f.

101 Vgl. Herzog, Rechtliche Sonderstellung der Oberlausitz (wie Anm. 2).

102 Vgl. Schmidt, Einschränkung der rechtlichen Sonderstellung (wie Anm. 2), S. 70; Schmidt, Staatsreform in Sachsen (wie Anm. 23), S. 180.

103 Gesetze und Verordnungen 1834 (wie Anm. 91), S. 484.

$104 \mathrm{Zu}$ den Gewerbeverhältnissen in der Oberlausitz, die auf einen Vertrag der Sechsstädte mit dem böhmischen König Ferdinand I. vom 15. September 1534 zurückgingen, vgl. ERHaRd HaRtstock, Wirtschaftsgeschichte der Oberlausitz 1547-1945, Bautzen 2007, S. $64 \mathrm{f}$. 
[etwas] geschmälert oder aufgehoben werden. ${ }^{105}$ Weitere Sonderrechte bezogen sich auf das von den Ständen ausgeübte Bergregal sowie ihre Jagd- und Fischereirechte. 106

Mit dem Scheitern der Revolution von 1848/49107 wurden die erneut laut gewordenen Forderungen nach einer Angleichung der Oberlausitzer Verhältnisse wiederum hinfällig. Nennenswert sind hier neben der Zusammenführung der sächsischen und oberlausitzischen Brandversicherungsanstalt eigentlich nur die Veränderungen in der Zusammensetzung der Provinzialstände, bei denen sich der Anteil der Landstädte von zwei auf sechs und der Bauern von 10 auf 50 Vertreter erhöhte. ${ }^{108}$

Obwohl die auf dem Traditionsrezess fußende Partikularverfassung vom 17. November 1834 die Oberlausitz endlich mit den sächsischen Erblanden zu einem Einheitsstaat verschmelzen ließ und sie, bis auf die Ausnahme im Kirchen- und Schul- sowie im Gewerbe- und Bergbaubereich, in der Folgezeit die Übernahme der meisten sächsischen Reformgesetze ermöglichte, behinderte sie doch spürbar die weitere Modernisierung der Oberlausitz. Vor allem in Hinblick auf die fortbestehenden ständischen Partikularrechte galt die Oberlausitz bald in Sachsen als die politisch und ökonomisch rückständigste Region. 109

\section{VI. Österreichische Proteste 1828-1845}

Wie die Partikularverfassung von 1834 zeigt, waren der Prager Traditionsrezess und -abschied Anfang der 1830er-Jahre für die sächsische Regierung in ihren Verhandlungen mit den Oberlausitzer Ständen noch immer die Gesprächsgrundlage, wenn es um den Fortbestand von deren Sonderrechten ging. Dass die sächsische Regierung zu diesem Zeitpunkt überhaupt noch auf die alten Verträge einging und sich bei der Integration der Oberlausitz nicht einfach darüber hinwegsetzte, ist sicherlich vor allem mit der außenpolitischen Rücksichtnahme auf Österreich zu

105 Sammlung der Gesetze und Verordnungen für das Königreich Sachsen 1834 (wie Anm. 91), S. 484.

106 Allgemein zu den Sonderrechten vgl. SснміDт, Einschränkung der rechtlichen Sonderstellung (wie Anm. 2), S. 76-83; Max Herzog zu Sachsen, Staatsrechtliche Stellung des Markgraftums Oberlausitz (wie Anm. 1), S. 27-54.

107 Beispielhaft sei hier verwiesen auf Martina Schattrowsky (Hg.), Dresdner Maiaufstand und Reichsverfassung 1849. Revolutionäres Nachbeben oder demokratische politische Kultur? (Schriften zur sächsischen Geschichte und Volkskunde 1), Leipzig 2000; Schmidt, Entwicklung der politischen Opposition (wie Anm. 82); Jörg Ludwig/ Andreas Neemann, Revolution in Sachsen 1848/49. Darstellung und Dokumente, Dresden 1999; Josef Matzerath, Der sächsische König und der Dresdner Maiaufstand. Tagebücher und Aufzeichnungen aus der Revolutionszeit 1848/1849 (Quellen und Materialien zur Geschichte der Wettiner 1), Köln 1999.

108 Vgl. Sснміdт, Einschränkung der rechtlichen Sonderstellung (wie Anm. 2), S. 80.

109 Vgl. ebd., S. 75-77. 
erklären. ${ }^{110}$ Gerade nach dem Teilungstrauma von 1815 benötigte Sachsen die Habsburgermonarchie als politisches Gegengewicht gegen die preußische Übermacht und die immer noch nicht überwundenen Annexionsängste. ${ }^{111}$ Hinzu kam, dass Sachsen selbst noch ungeklärte territoriale Ansprüche gegenüber Österreich besaß: Als Kriegsverlierer hatte Friedrich August I. Schwierigkeiten, die ihm 1809 im Frieden von Schönbrunn übertragenen böhmischen Enklaven in der Oberlausitz auch weiterhin als legitime Kriegsentschädigung zu beanspruchen. Bezeichnenderweise nahm Österreich von seinen verloren gegangenen Exklaven nicht einfach militärisch Besitz, sondern setzte ebenfalls auf den Verhandlungsweg. Der daher lange Zeit ungeklärte Status der böhmischen Enklaven führte unter anderem dazu, dass die Stadt Schirgiswalde bis zur abschließenden sächsisch-böhmischen Einigung 1845 an keine der beiden Seiten mehr Steuern abführte und sich stattdessen einen Namen als „Schmuggel- und Glücksspiel-Paradies“ machte.112

Wie bereits geschildert, stellte die sächsische Regierung die Gültigkeit der im Traditionsrezess formulierten Bestimmungen für die staatliche Sonderstellung der Oberlausitz nicht gänzlich in Frage, sondern vor allem die dem eigenen Souveränitätsverständnis entgegenstehenden böhmischen Kirchenaufsichts- und Lehnsrechte. Als 1827 mit dem Tod Friedrich Augusts I. erstmals seit dem österreichischen Thronwechsel von 1792 wieder der Lehnsfall eintrat, garantierte sein Nachfolger Anton daher zwar verfassungskonform den Oberlausitzer Ständen, ihre Rechte gemäß dem Traditionsrezess zu wahren, suchte aber erstmals seit 1635 nicht mehr in Wien um eine Lehnserneuerung nach. ${ }^{113}$ Es wird daher kein Zufall sein, dass just 1828 Österreich erneut auf seine Rechtsansprüche verwies. ${ }^{114}$

Dass der Wiener Hof auch der in Vorbereitung der sächsischen Verfassung diskutierten Integration der Oberlausitz nicht stillschweigend zusehen würde, zeigte sich bereits im April 1831 als die österreichische Regierung sowohl gegen die geplante Eingliederung der Oberlausitz als auch gegen die nun festgesetzte Erbfolge der Wettiner protestierte und mit Verweis auf den Traditionsrezess die Aufnahme der böhmischen Oberaufsichtsrechte über die katholischen Kirchen-

110 So auch Sснміdт, Einschränkung der rechtlichen Sonderstellung (wie Anm. 2), S. 71.

111 Vgl. z. B. Katrin Keller, Landesgeschichte Sachsen (UTB 2291), Stuttgart 2002, S. 262; Ulrike Kirchberg, Zwischen Politik und Freundschaft. Hansy, Dicki, Franz - Sachsen, Preußen, Österreich, in: Zwischen zwei Welten. König Johann von Sachsen, hrsg. von der Sächsischen Schlösserverwaltung und dem Staatlichen Schlossbetrieb Schloss Weesenstein, Halle an der Saale 2001, S. 169-173, hier S. 169.

$112 \mathrm{Zu}$ den böhmischen Enklaven in der Oberlausitz vgl. mit weiterführenden Literaturhinweisen: Kathrin Lehnert, Die Un-Ordnung der Grenze. Mobiler Alltag zwischen Sachsen und Böhmen und die Produktion von Migration im 19. Jahrhundert (Schriften zur sächsischen Geschichte und Volkskunde 56), Leipzig 2017, S. 66-80, 187-203, hier zitiert S. 67; speziell zur sogenannten Republik Schirgiswalde vgl. Rolf VIEwEG, Die böhmische Enklave Schirgiswalde zwischen Österreich und Sachsen von 1809 bis 1845, Hamburg 21999.

113 Vgl. Thümmel, Wem gehört die Oberlausitz (wie Anm. 1), S. 50.

114 Vgl. ebd., S. 58. 
einrichtungen in die sächsische Verfassungsurkunde forderte. ${ }^{115}$ Auch gegen die im Dezember 1831 vom Bautzener Domkapitel ohne böhmische Beteiligung durchgeführte Wahl116 eines neuen Dekans legte Österreich Protest ein. In der österreichischen Position scheint sich damit ebenfalls ein Strategiewechsel anzudeuten: Beansprucht wurde nun vorrangig nicht mehr die von Sachsen so vehement bestrittene böhmische Lehnsherrlichkeit, wohl aber die Sukzessions- und Kirchenaufsichtsrechte.

Zwischenzeitlich waren die österreichischen Forderungen auch in anderen Staaten bekannt geworden und hatten insbesondere das preußische Interesse geweckt. Berlin hatte sich zwar 1815 in der Wiener Kongressakte ausdrücklich den österreichischen Verzicht auf die lehnsherrlichen Rechte über die von Sachsen abgetretenen Teile der Lausitzen bestätigen lassen, trotzdem war aber auch in Preußen deren Rechtsstatus nicht unumstritten. Beispielweise war es 1815 „lange Zeit unentschieden [gewesen], ob Preußen nur mit seinen ehemaligen Reichsterritorien oder auch mit den vom alten Reiche als gänzlich unabhängig angesehenen neuerworbenen Lausitzer Gebietsteilen und Schlesien in den Deutschen Bund eintritt." 117 Zudem hatte auch Preußen 1815 im Staatsvertrag mit Österreich den Erhalt der geistlichen Stiftungen garantieren müssen, sodass etwa das Kloster Neuzelle nicht privatisiert oder in ein Staatsgut umgewandelt werden konnte, sondern als Stiftung weiterbestand. ${ }^{118}$

Infolge der österreichischen Einsprüche ließ die sächsische Regierung die Rechtsverhältnisse noch einmal gründlich prüfen und überlegte 1831/32 sogar, das Bautzener Kollegiatstift in ein Hochstift zu erheben und zusammen mit der katholischen Kirche in den Erblanden daraus ein katholisches Landesbistum zu gründen, um so die böhmischen Aufsichtsrechte in der Oberlausitz „abzuschüt-

$115 \mathrm{Zu}$ den österreichischen Protesten und den sich bis 1845 hinziehenden österreichischsächsischen Konflikten vgl. SснміDт, Einschränkung der rechtlichen Sonderstellung (wie Anm. 2), S. 72-75; Ders., Staatsreform in Sachsen (wie Anm. 23), S. 182-187; Lammel, Habsburg und die Oberlausitz (wie Anm. 2), S. 234 f.; Deumer, Rechtlicher Anspruch Böhmen-Österreichs (wie Anm. 1), S. 60-63.

116 Ausführlicher zur Wahl vgl. Heinrich Meier, Das Apostolische Vikariat in den Sächsischen Erblanden (Studien zur katholischen Bistums- und Klostergeschichte 24), Leipzig 1981, S. 168-175; Ders., Die katholische Kirche in Sachsen in der ersten Hälfte des 19. Jahrhunderts. Eine Untersuchung zur Rechts- und Verfassungsgeschichte (Studien zur katholischen Bistums- und Klostergeschichte 15), Leipzig 1974, S. 52-54.

117 Vgl. Thüмmel, Wem gehört die Oberlausitz (wie Anm. 1), S. 55 f.

118 Vgl. Töpler, Kloster Neuzelle (wie Anm. 17), S. 150. Töpler sieht daher auch für die Niederlausitz noch auf den Traditionsrezess zurückgehende Folgen: „Ohne die kirchenrechtlichen Reservate im Traditionsrezess von 1635 hätte es den Artikel 16 im Staatsvertrag von 1815 nicht gegeben, und ohne diesen das Stift Neuzelle (des 19. Jahrhunderts) nicht." Auch die 1996 vom Land Brandenburg ins Leben gerufene Stiftung „Stift Neuzelle“ belegt somit letztlich „aus dem Blickwinkel historischer Dimensionen [...] noch heute die Präsenz des Kaisers in der Niederlausitz.“ 
teln“.119 Im Ergebnis erklärte die sächsische Regierung mit Verweis auf die 1806 und 1815 geschlossenen Verträge nochmals die österreichischen Ansprüche als erloschen. Zugleich wurde betont, dass es sich bei den ohne jeglichen Druck erfolgten Verhandlungen mit den oberlausitzischen Ständen hinsichtlich einer Abänderung ihrer auf dem Traditionsrezess beruhenden Provinzialverfassung um ein legitimes Vorgehen des sächsischen Königs handele. Gerade diesem betonten Fehlen jeglicher Willkür seitens des sächsischen Königs scheint eine strategische Bedeutung innegewohnt zu haben. Denn solange die Übereinkunft mit den Oberlausitzer Ständen auf „vollkommen freiwillig[er]“ Basis erfolgte, solange gab es seitens der Provinzialstände auch keine Veranlassung oder gar Legitimation, Österreich als Schutzmacht anzurufen. Denn wenngleich die sächsische Regierung einer ständischen Beschwerde am Wiener Hof - schon allein der sächsischen und österreichischen Mitgliedschaft im Deutschen Bund wegen - keine Erfolgsaussichten zumaß, so rechnete sie doch fest mit einem solchen Schritt der oberlausitzischen Stände. ${ }^{120}$

Diese Strategie scheint in der Tat auch aufgegangen zu sein: Seit der gütlichen Einigung der sächsischen Regierung mit den Oberlausitzer Ständen vom 9. Dezember 1832 unternahm der Wiener Hof erst einmal keine weiteren diplomatischen Schritte mehr. Erst 1841/42 bei der wieder ohne Hinzuziehung Böhmens erfolgten Wahl eines neuen Bautzener Dekans entflammte der Konflikt aufs Neue. Das Bautzener Domkapitel hatte den sächsischen König zwar nach dem Tod des bisherigen Dekans noch gebeten, die Neuwahl solange auszusetzen, bis es zu einer Einigung mit Österreich gekommen sei, die sächsische Regierung wollte aber unbedingt einer möglichen österreichischen Initiative zuvorkommen und die Wahl so schnell wie möglich erledigt wissen. ${ }^{121}$ Erneut intervenierte also Österreich und erneut ließ die sächsische Regierung die eventuelle Gültigkeit des Traditionsrezesses gründlich prüfen. Diesmal wurde sogar eine spezielle Kommission ins Leben gerufen, deren abschließendes Gutachten vom 24. Februar 1842 allein 241 Seiten umfasste. Im Mai 1842 schlug der Wiener Hof vor, nicht nur seine strittigen Sukzessions- und Kirchenaufsichtsrechte, sondern auch seine Lehnsansprüche vor dem Austrägalgericht des Deutschen Bundes zu verhandeln. Sachsen, das eine zu große Einflussnahme Österreichs auf dieses Schiedsgericht befürchtete, drängte stattdessen darauf, Preußen als Vermittler heranzuziehen.122 Beide Vorschläge verliefen im Sande, und so sollte es weitere drei Jahre dauern, bis beiden Seiten eine gütliche Einigung gelang. Im Gegenzug für die am 9. Mai 1845 vom sächsischen

119 Sснміdт, Einschränkung der rechtlichen Sonderstellung (wie Anm. 2), S. 73 f.; ausführlicher zu den Plänen eines Landesbistums vgl. MeIER, Die katholische Kirche in Sachsen (wie Anm. 116), S. 54-65.

120 Vgl. ebd., S. 74; Sснмidt, Staatsreform in Sachsen (wie Anm. 23), S. 185 f.

121 Vgl. MeIer, Das Apostolische Vikariat (wie Anm. 116), S. 175-177; Ders., Die katholische Kirche in Sachsen (wie Anm. 116), S. 65-68.

122 Vgl. Deumer, Rechtlicher Anspruch Böhmen-Österreichs (wie Anm. 1), S. 61; TнüMMEL, Wem gehört die Oberlausitz (wie Anm. 1), S. 58. 
König schriftlich gegebene Garantie, die im Traditionsrezess verankerte Verfassung und Rechte des Bautzener Domkapitels und der beiden Oberlausitzer Nonnenklöster ungeschmälert zu wahren, verzichtete die österreichische Regierung am 21. Mai 1845 darauf, fortan in die Fübrung der inneren und äusseren Angelegenheiten dieser Stifter, insbesondere auch auf Alles, was sich auf die Wabl ibrer Vorsteber beziebt, einzugreifen. ${ }^{123}$

\section{Das Ende der Sonderstellung - staatsrechtliche Bedenken und die weitere Entwicklung nach 1845}

Ob mit dem Austausch der beiden Urkunden am 6. Juni 1845 in Wien „die Oberlausitz [...] nun endgültig von allen auswärtigen Bindungen und Verpflichtungen frei“ war - wie dies Gerhard Schmidt postulierte ${ }^{124}$ - hängt auch heute noch vom jeweiligen Standpunkt des Betrachters ab und ist bei Schmidt wohl darauf zurückzuführen, dass Österreich nach 1845 seine Forderungen nicht mehr wiederholte und auch nicht mehr direkt in die oberlausitzischen Stiftswahlen eingriff. Trotzdem hatten die Habsburger ihren Einfluss auf die katholische Kirche in der Oberlausitz nicht gänzlich verloren, da weiterhin die dortigen katholischen Theologen in Prag studierten, die beiden exemten Klöster dem böhmischen Kloster Ossegg unterstanden und von diesem auch mit neuen geistlichen und weltlichen Direktoren versorgt wurden. ${ }^{125}$ Zudem hatte der Wiener Hof keinesfalls auf seine Ansprüche verzichtet und sollte auch bis zum Ende der Monarchie daran festhalten. Nur drei Jahre nach dem erreichten Vergleich von 1845 vertrat beispielsweise der österreichische Ministerpräsident Johann Philipp von Wessenberg (1773-1858) ${ }^{126}$ weiterhin die Auffassung, dass seinem Land hinsichtlich der Oberlausitz noch immer die Oberlehnsherrlichkeit, das Schutzrecht über die katholische Religion sowie ein eventuelles Einlösungs- und Heimfallrecht zustanden. ${ }^{127}$ Am Führen des markgräflichen Titels und Wappens beider Lausitzen hielten die Habsburger sogar über das Ende der Monarchie hinweg fest. Noch im Juli 2011 wurde der letzte österreichische Kronprinz, Otto [von] Habsburg (1912-2011), bei seiner Bestattung als Markgraf der Ober- und Niederlausitz betitelt, ${ }^{128}$ so wie schon zuvor im

123 Zitiert nach Deumer, Rechtlicher Anspruch Böhmen-Österreichs (wie Anm. 1), S. 62 f.

124 Schmidt, Staatsreform in Sachsen (wie Anm. 23), S. 187; Ders., Einschränkung der rechtlichen Sonderstellung (wie Anm. 2), S. 75.

125 Vgl. Lammel, Habsburg und die Oberlausitz (wie Anm. 2), S. 237 f.; Pfeiffer, Verhältnis der Oberlausitz zur Krone Böhmen (wie Anm. 1), S. 93.

126 Vgl. Alfred Ritter von Arneth, Wessenberg, Johann Freiherr von, in: Allgemeine Deutsche Biographie 42 (1897), S. 157-173, online: www.deutsche-biographie.de.

127 Vgl. Lammel, Habsburg und die Oberlausitz (wie Anm. 2), S. 235. Mit weiteren Beispielen vgl. Deumer, Rechtlicher Anspruch Böhmen-Österreichs (wie Anm. 1), S. 65 f.; PfeIffer, Verhältnis der Oberlausitz zur Krone Böhmen (wie Anm. 1), S. 96-100.

128 Vgl. z. B. diepresse.com/home/politik/zeitgeschichte/677366/Klopfzeremonie_Werbegehrt-Einlass [Zugriff: 15. Februar 2012]. 
März 1989 seine Mutter, die ehemalige Kaiserin Zita (1892-1989).129 Diesen Anspruch hatten auch die sächsischen Könige - die laut Paragraf 4 des sächsisch-preußischen Friedensvertrags vom 18. Mai 1815 (im Gegensatz zu den preuBischen Königen als den neuen Markgrafen beider Lausitzen) selbst nur noch den Titel eines Markgrafen der Oberlausitz führen durften ${ }^{130}$ - nicht bestritten. ${ }^{131}$

1845 hatte man sich also letztlich nur auf einen Modus Vivendi geeinigt, um zukünftigen Konflikten vorzubeugen. Hinsichtlich der Rechtsgiltigkeit des Traditionsreceßes war es zu keiner abschließenden Klärung gekommen, sondern beide Seiten hatten nur vertraglich festgehalten, dass sie hierüber unterschiedlicher Auffassung waren. ${ }^{132}$ Eine endgültige Entscheidung war somit 1845 erneut in die Zukunft verschoben worden, und auch für die sächsische Regierung, die von Österreich eine ähnliche Verzichtserklärung wie 1815 für Preußen erhofft hatte, blieb der erzielte Vergleich so nur von halbherziger Natur. Die Zweite Kammer des Sächsischen Landtags kam 1848 sogar zu dem Schluss, die sächsische Regierung hätte mit ihrem Dekret vom 9. Mai 1845 dem Wiener Hof ein Oberhoheitsrecht über die katholischen Klöster eingeräumt, was der Zustimmung der Stände bedurft hätte, weshalb sie die Rechtsgültigkeit des Vertrags bestritt. ${ }^{133}$

Auch die eingangs bereits angeführten, späteren juristischen Schriften - beginnend mit Julius Pfeiffer (1873) über Heinrich Deumer (1884) bis hin zu Max Herzog zu Sachsen (1892) ${ }^{134}$ - bezweifelten die Stichhaltigkeit der sächsischen Argumentationen. Bezeichnenderweise konnten aber auch sie die kontrovers diskutierte Rechtsstellung der Oberlausitz im Königreich Sachsen nicht abschließend klären. Allesamt kamen sie aber zu dem Schluss, dass Österreich durchaus noch juristische Ansprüche an der Oberlausitz besitze:

Julius Pfeiffer fand 1873 sowohl „Gründe für und wider die Fortdauer der Rechtsgültigkeit des Traditionsrezesses von 1635“,135 und selbst Max Herzog zu Sachsen, als Mitglied des regierenden Fürstenhauses, maß dem Traditionsrezess für die gültigen Rechtsverhältnisse der Oberlausitz 1892 noch eine „gewisse, wenn auch mittelbare Bedeutung“ zu. ${ }^{136}$ Seiner Ansicht nach könnte das Lehnsverhält-

129 Vgl. Lammel, Habsburg und die Oberlausitz (wie Anm. 2), S. 231.

130 Zitiert nach Blaschke, Bewahrte Einheit (wie Anm. 69), S. 273. Zum sächsisch-preuBischen Friedensvertrag vgl. Blank, Der bestrafte König (wie Anm. 42), S. 257-261.

131 Vgl. Deumer, Rechtlicher Anspruch Böhmen-Österreichs (wie Anm. 1), S. 74.

132 Zitiert nach Pfeiffer, Verhältnis der Oberlausitz zur Krone Böhmen (wie Anm. 1), S. $90 \mathrm{f}$.

133 Vgl. Deumer, Rechtlicher Anspruch Böhmen-Österreichs (wie Anm. 1), S. 64; Pfeiffer, Verhältnis der Oberlausitz zur Krone Böhmen (wie Anm. 1), S. 97.

134 Vgl. oben, Anm. 1.

135 So bereits der Titel des ersten Kapitels bei: Pfeiffer, Verhältnis der Oberlausitz zur Krone Böhmen (wie Anm. 1), S. 86-90.

136 Max Herzog zu Sachsen, Staatsrechtliche Stellung des Markgraftums Oberlausitz (wie Anm. 1), S. 3: „Der Traditionsrezess bildet für die Kenntnis der staatsrechtlichen Stellung der Oberlausitz die wichtigste Grundlage, er ist das Staatsgrundgesetz derselben, und ist auch noch für die heutigen Rechtsverhältnisse derselben von einer gewissen, wenn auch mehr mittelbaren Bedeutung“. 
nis eventuell über die Jahre 1831 beziehungsweise 1834 hinaus bestanden haben, er braucht diese Frage aber in seiner Dissertation nicht mehr tiefergehend analysieren, da für ihn Österreich spätestens 1866 stillschweigend auf seine Ansprüche verzichtet hatte, als es im Prager Frieden vom 23. August 1866 zwar der Neugestaltung Deutschlands zustimmte, dabei aber versäumte, seine Rechte an der Oberlausitz vertraglich festzuhalten. ${ }^{137}$ Diese Rechtsauffassung hatte hingegen Heinrich Deumer bereits 1884 abgelehnt. Da es durch den Beitritt Sachsens zum Norddeutschen Bund zu keinen Gebietsveränderungen hinsichtlich der Oberlausitz gekommen war, sah er keinen Grund, warum Wien seine Ansprüche im Prager Frieden hätte ansprechen sollen. ${ }^{138}$ Auch die übliche Auffassung, die böhmischen Rechte wären bereits durch die Verträge von 1806 beziehungsweise 1815 erloschen, konnte er nicht teilen. ${ }^{139}$ Seiner Ansicht nach, bezog sich die 1806 gewonnene sächsische Souveränität nur auf Lehnsverhältnisse zum Reich, nicht aber auf die Lausitzen als böhmisches Lehen. So hätte zwar der sächsische Kurfürst mit der Auflösung des Alten Reichs und seiner Erhebung zum König seine volle Souveränität erlangt, nicht aber der oberlausitzische Markgraf, der weiterhin Vasall der böhmischen Krone geblieben sei. Auch die Rheinbundakte habe die böhmischen Lehnsverbindungen nicht aufgehoben, da sich die Rheinbundsouveränität nur auf Lehnsverhältnisse innerhalb des Bundes bezog.

Erst mit der Wiener Kongressakte hätte, laut Deumer, der österreichische Kaiser als Rechtsnachfolger des böhmischen Königs seine lehnsherrlichen Rechte über die Lausitzen niedergelegt, diese Verzichtserklärung aber ausdrücklich nur auf diejenigen Gebiete bezogen, die nicht bei Sachsen verblieben, also auf die an Preußen abgetretene Niederlausitz und den entsprechenden Teil der Oberlausitz. Die nach der Teilung von 1815 bei Sachsen verbliebene restliche Oberlausitz sei somit böhmisches Lehen geblieben, und diese Rechtsstellung der sächsischen Oberlausitz habe mit der Kongressakte ihre völkerrechtliche Bestätigung gefunden. Zuletzt betonte 2004 auch der Görlitzer Notar Hans-Wolf Thümmel, dass er die in der landesgeschichtlichen Forschung vertretene Auffassung, die lehnsrechtliche Stellung der Oberlausitz sei von Beginn an „eine gegenstandslose Formsache gewesen“, „vom juristischen Standpunkt aus nicht teilen“ könne. ${ }^{140}$

Eine größere Bedeutung als der Lehnsbindung wurde hingegen der Sukzessionsfrage und dem Heimfallrecht beigemessen. Entsprechend der im Traditionsrezess festgehaltenen, möglichen Nachfolge der Töchter Kurfürst Johann Georgs I. hätten Ende des 19. Jahrhunderts bei einem eventuellen Aussterben der Albertiner die Häuser Hessen-Darmstadt, Oldenburg und Russland sowie die Nachkommen des Hauses Wasa einen Anspruch auf die Sukzession in der Ober-

137 Vgl. ebd., S. 48 f.

138 Vgl. Deumer, Rechtlicher Anspruch Böhmen-Österreichs (wie Anm. 1), S. 69.

$139 \mathrm{Zu}$ dessen juristischen Argumentationen und Wertungen vgl. ausführlicher: Deumer, Rechtlicher Anspruch Böhmen-Österreichs (wie Anm. 1), S. 13-20.

140 Thümmel, Wem gehört die Oberlausitz (wie Anm. 1), S. 51. 
lausitz geltend machen können. ${ }^{141}$ Zuvor hätte Österreich in einem solchen Fall das Recht besessen, die Oberlausitz gegen die 1635 zugesicherte Pfandzahlung wieder auszulösen. Nach dem Aussterben aller berechtigten Häuser hätte die Oberlausitz entschädigungslos an Österreich fallen sollen. Eine solche Rückübertragung sahen die Juristen aber spätestens mit dem Beitritt Sachsens zum Norddeutschen Bund 1866 beziehungsweise der Gründung des Deutschen Reiches 1871 als hinfällig an. Denn selbst wenn auf der Grundlage der Partikularverfassung vom 17. November 1834 die Oberlausitz nach dem Aussterben der albertinischen Wettiner aus dem sächsischen Staatsverband herausgelöst werden sollte, so würde die Übertragung eines deutschen Landesteils an eine ausländische Macht gegen die Grundprinzipien der Reichsverfassung verstoßen. Einen solchen Schritt hätten aus Sicht der sächsischen Staatsrechtler weder der Norddeutsche Bund noch das Deutsche Reich zugelassen. Auch Deumer sah keine Heimfallmöglichkeit an Österreich mehr, gab aber zu bedenken, dass die Oberlausitz durchaus noch innerhalb des Reichsverbandes wechseln könnte, eine Anspielung auf das Sukzessionsrecht Hessen-Darmstadts. ${ }^{142}$

Trotz aller vorgebrachten Argumente für eine mögliche rechtliche Legitimation der österreichischen Forderungen erkannte aber keiner der Autoren im ausgehenden 19. Jahrhundert darin noch eine praktische Bedeutung. Denn selbst wenn bis zu einer offiziellen österreichischen „Verzichtsleistung“ die alten Konflikte jederzeit wieder aufflammen könnten, würden „die besten Rechtsgründe [...] nichts vermögen“, wenn man sie - wie es Julius Pfeiffer auf den Punkt brachte ${ }^{143}$ - politisch nicht durchsetzen könnte, wozu Österreich spätestens seit der sogenannten kleindeutschen Lösung nicht mehr in der Lage war.

Dass sich seit der Reichsgründung 1871 gleich mehrere sächsische Staatsrechtler mit einem aus landesgeschichtlicher Sicht doch vermeintlich längst erledigten Thema beschäftigten, besaß unter anderem in der aufkommenden panslawistischen Bewegung, in deren Zuge seit der zweiten Hälfte des 19. Jahrhunderts auch die Frage nach der politischen Zugehörigkeit der sorbischen Bevölkerung der Lausitzen gestellt worden ist, einen konkreten Hintergrund. „Die mögliche Fortgeltung des Traditionsrezesses“ und die damit einhergehende Option eines Heimfalls der sächsischen Oberlausitz an Böhmen sowie die dann bereits diskutierte Einbeziehung in einen zu gründenden tschechischen Nationalstaat „wurde von ängstlichen Gemütern [nun] als nationale Gefahr“ verstanden. ${ }^{144}$ Auch Julius Pfeiffer begrün-

141 Vgl. Max Herzog zu Sachsen, Staatsrechtliche Stellung des Markgraftums Oberlausitz (wie Anm. 1), S. 49-54; DeUmer, Rechtlicher Anspruch Böhmen-Österreichs (wie Anm. 1), S. 9, 20; Pfeiffer, Verhältnis der Oberlausitz zur Krone Böhmen (wie Anm. 1), S. $99 \mathrm{f}$.

142 Vgl. Deumer, Rechtlicher Anspruch Böhmen-Österreichs (wie Anm. 1), S. 73.

143 Vgl. Pfeiffer, Verhältnis der Oberlausitz zur Krone Böhmen (wie Anm. 1), S. 90.

144 Vgl. Thümmel, Wem gehört die Oberlausitz (wie Anm. 1), S. 63 f., Zitate = S. 64; Lammel, Habsburg und die Oberlausitz (wie Anm. 2), S. 235. - Zur sorbischen Nationalbewegung vgl. Friedrich W. Remes, Die Sorbenfrage 1918/1919. Untersuchung einer gescheiterten Autonomiebewegung (Schriften des Sorbischen Instituts 3), Bautzen 1993, zur Berufung auf den Traditionsrezess hier insbesondere S. 82-89. 
dete 1873 seine Studie mit der im Rahmen der tschechischen Nationalbewegung geforderten Revindication der Lausitz an Böhmen. Diese mit Verweis auf das im Traditionsrezess enthaltene böhmische Heimfallrecht geforderte Rückführung nahm Pfeiffer zum Anlass, „jene alten Verträge, auf welche die Krone Böhmen ihre Ansprüche gründet, noch einmal an das Tageslicht zu bringen, einer genauen Betrachtung zu unterziehen, und zu prüfen, ob sie denn wirklich noch zur Recht bestehen, und gegenwärtig oder künftig einen Einfluß auf die Zustände der Oberlausitz und deren eventuelle Staatsangehörigkeit ausüben können“.145 Der bisherige Schutzcharakter des Traditionsrezesses für die oberlausitzische Sonderverfassung hatte sich also gedreht und wurde nun zum Teil von einem nationalen Bedrohungsszenario überlagert. Vor allem „die Orientierung der Katholiken nach Böhmen und [...] die Ausbildung der sorbischen Geistlichkeit am Wendischen Seminar in Prag wurde dadurch verdächtig “. .146

Mit dem Aufsatz von Pfeiffer beginnend wurden ab 1873 die einzelnen Bestimmungen des Traditionsrezesses mehrfach darauf analysiert, inwiefern sich dahinter nicht doch noch österreichische Ansprüche verbargen. In diesem Zusammenhang wurden auch die verfassungsmäßigen Sonderrechte der Oberlausitz mit angesprochen, die - auf dem Traditionsrezess von 1635 fußend und weiterhin von der Partikularverfassung von 1834 geschützt - vor allem im Bereich der Kirchenverfassung und Gesetzgebung gültig geblieben waren, teilweise sogar bis ins 20. Jahrhundert hinein. ${ }^{147}$

Auf die legislativen Sonderrechte der Provinzialstände, denen jedes sächsische Gesetz vor der Inkraftsetzung in der Oberlausitz zur Begutachtung vorzulegen war, ist bereits hingewiesen worden. Mit dieser Verfahrensweise konnten die Unterschiede in der Gesetzgebung zwar in den 1830er- und 1840er-Jahren weitgehend angeglichen werden, die Oberlausitzer Stände besaßen aber - im Gegensatz zur Auffassung in der landesgeschichtlichen Literatur - weiterhin ein Vetorecht bei der Einführung aller sächsischen Gesetze. Dieses Einspruchsrecht galt auch noch nach der Gründung des Norddeutschen Bundes beziehungsweise des Kaiserreiches, bezog sich dann allerdings weiterhin nur auf die sächsischen und nicht auf die übergeordneten Bundes- beziehungsweise Reichsgesetze. ${ }^{148}$

Zwei Beispiele, bei denen die Oberlausitzer Stände im Gesetzgebungsverfahren die Berücksichtigung ihrer Sonderrechte eingefordert haben, sind die Einführung des sächsischen Gewerbegesetzes 1861 sowie des sächsischen Berggesetzes 1868. Mit Rücksicht auf die „wirtschaftliche Bedeutung und [das] Gewicht der Handwerke und der Hausindustrie innerhalb der sächsischen Wirtschaft und Ge-

145 Vgl. Pfeiffer, Verhältnis der Oberlausitz zur Krone Böhmen (wie Anm. 1), S. 77 f.

146 Vgl. Thüмmel, Wem gehört die Oberlausitz (wie Anm. 1), S. 63.

$147 \mathrm{Zu}$ diesen noch gültigen Sonderrechten vgl. zusammenfassend z. B. Sснмidt, Einschränkung der rechtlichen Sonderstellung (wie Anm. 2), S. 76-83; Max Herzog zU SAchsen, Staatsrechtliche Stellung des Markgraftums Oberlausitz (wie Anm. 1), S. 2754.

148 Vgl. SснміDт, Einschränkung der rechtlichen Sonderstellung (wie Anm. 2), S. 78, 81. 
sellschaft“, aber auch aus „Furcht vor Konflikten“ hatte das Königreich Sachsen die Gewerbefreiheit erst sehr spät mit dem Gewerbegesetz vom 15. Oktober 1861 umgesetzt. ${ }^{149} \mathrm{Da}$ das Gewerbegesetz aber in die Partikularverfassung von 1834 eingriff, musste mit der Oberlausitz über eine entsprechende Anpassung von Paragraf 5 verhandelt werden. Im Ergebnis stimmten auch die Provinzialstände der Einführung des Gewerbegesetzes zum 1. Januar 1862 in der Oberlausitz zu, ließen sich aber in der notwendigen Verfassungsänderung zusichern, dass eine Beschränkung der in dem Gewerbegesetze festgestellten Gewerbefreibeit in der Oberlausitz auch künftig nicht obne Zustimmen der Provincialstände eingeführt werden darf. ${ }^{150}$ Aufgrund dieser Zusicherung war die sächsische Regierung sogar „verpflichtet gewesen“, im Bundesrat bei den Verhandlungen zur Reichsgewerbeordnung gegen alle Paragrafen Einspruch zu erheben, die auf eine Einschränkung der Gewerbefreiheit in der Oberlausitz hinausliefen. ${ }^{151}$ Mit der übergeordneten Reichsgewerbeordnung vom 21. Juni 1869 waren dann aber auch die Oberlausitzer Vorbehalte hinsichtlich der sächsischen Gewerbeordnung „praktisch bedeutungslos geworden". .152

Ähnlich verlief es in einem weiteren, in der Landesgeschichte bislang noch nicht berücksichtigten Fallbeispiel: der Übernahme der sächsischen Berggesetze. ${ }^{153}$ Auch das Bergregal der Oberlausitzer Stände auf den Abbau von edlen und unedlen Metallen war durch den Traditionsrezess und entsprechend durch die Partikularverfassung geschützt. Den Lausitzer Ständen war es hier im Verlauf des 17. und 18. Jahrhunderts sogar gelungen, ihre Rechte über den Stand von $1635 \mathrm{zu}$ erweitern. ${ }^{154}$ Noch 1851 konnte die Oberlausitz daher nicht in den Geltungsbereich des neu erlassenen sächsischen Gesetz[es] über den Regalbergbau einbezogen werden, und auch das umfassendere Allgemeine sächsische Berggesetz vom 16. Juni 1868 erlangte nur beim Kohlenbergbau - auf den sich nach sächsischer

149 Zur Reform der sächsischen Gewerbegesetzgebung im Königreich Sachsen vgl. HubERT KIESEWETTER, Die Industrialisierung Sachsens. Ein regional-vergleichendes Erklärungsmodell (Regionale Industrialisierung 5), Stuttgart 2007, S. 141-162, hier zitiert S. 162.

150 Paragraf 2 der Verordnung, die Einfübrung des Gewerbegesetzes in der Oberlausitz betreffend, vom 15. Oktober 1861; hier zitiert nach Deumer, Rechtlicher Anspruch Böhmen-Österreichs (wie Anm. 1), S. 39.

151 Vgl. Deumer, Rechtlicher Anspruch Böhmen-Österreichs (wie Anm. 1), S. 40.

152 Max Herzog zu Sachsen, Staatsrechtliche Stellung des Markgraftums Oberlausitz (wie Anm. 1), S. 31.

153 Auch in den Arbeiten von Gerhard Schmidt findet die Übertragung der sächsischen Berggesetze auf die Oberlausitz keine weitere Beachtung, sicherlich weil die Landesgeschichte hier von einem recht schnellen Erlöschen des ohnehin nicht so weitreichenden oberlausitzischen Bergregals ausgegangen war. Dem entsprechenden Wikipedia-Artikel zum Allgemeinen sächsischen Berggesetz zufolge sollen die Sonderrechte der oberlausitzischen Stände beispielsweise mit dem Gesetz über den Regalbergbau vom 22. Mai 1851 erloschen sein; de.wikipedia.org/wiki/Allgemeines_Berggesetz_für_das_König reich_Sachsen [Zugriff: 12. August 2018].

154 Vgl. Hermann Löscher, Auseinandersetzungen über das Bergrecht der Oberlausitz im 17. Jahrhundert, in: Martin Reuther (Hg.), Oberlausitzer Forschungen. Beiträge zur Landesgeschichte, Leipzig 1961, S. 143-155, hier S. 154 f. 
Sicht die Partikularverfassung nicht bezog - seine Geltung in der Oberlausitz. ${ }^{155}$ Auch das Gesetz, die Erstreckung des Allgemeinen Berggesetzes auf den Erzbergbau in der Oberlausitz betreffend, hielt am 24. Mai 1904 erneut nur die weiteren Beschränkungen fest, die für die Übernahme des sächsischen Berggesetzes von 1868 in der Oberlausitz gelten sollten. Als daher im Januar 1909 im Sächsischen Landtag die Gültigkeit der Bestimmungen über radiumbaltige Mineralien und radioaktive Gewässer in der Oberlausitz verhandelt wurden, kam in der Zweiten Kammer immer noch der Einspruch auf, dass hierfür auch der Tradionsrezeß vom Jabre 1635 zu prüfen wäre und dass selbst die Juristen hinsichtlich der rechtlichen Eigentümlicbkeiten der Oberlausitz keine eindeutige Antwort hätten. Da jedoch die Wabrscheinlichkeit sehr gering [war], daß Radium auf Oberlausitzer Rittergutsfluren je gewonnen werden könnte, wurde empfohlen, der Frage keine praktische Bedeutung mehr beizumessen. ${ }^{156}$

Besonders augenfällig zeigten sich die überkommenen Verhältnisse im kirchlichen Bereich, ${ }^{157}$ wo sich der Schutz der alten Verfassung bis in das Besetzungsrecht der einzelnen Pfarreien auswirkte. Im Gegensatz zum landesherrlichen Kirchenregiment in den Erblanden erstreckte sich das landesherrliche Patronat in der Oberlausitz am Ende des 19. Jahrhunderts auf gerade einmal fünf der 125 Pfarrstellen. ${ }^{158}$ Die Oberlausitzer Pfarrer wurden somit noch immer nicht von geistli-

155 Vgl. G[eorg] H[einrich] Wahle, Das Allgemeine Berggesetz für das Königreich Sachsen, Freiberg 1891, S. 32 f., 38 f.; laut Wahle sollten die in den Verhandlungen vorgebrachten „Wünsche“ der Oberlausitzer Stände, damit das gesamte Gesetz dann auch in deren Amtsbereich Gültigkeit erlangen würde, in späteren Verordnungen „gewissenhaft berücksichtigt“" werden. Zum Zeitpunkt seiner Studie (1891) war dies aber weder auf Landes- noch auf Reichsebene geschehen und das Allgemeine sächsische Berggesetz von 1868 somit immer noch nicht auf die Oberlausitz übertragen; ebd. S. 39.

156 Vgl. Mitteilungen über die Verhandlungen des ordentlichen Landtags im Königreiche Sachsen während der Jahre 1908-1909, Zweite Kammer, Bd. 5, Dresden 1909, S. 5179 f. - Auch in einer Verhandlung der Ersten Kammer über die Übertragung des Berggesetzes auf die Oberlausitz wurde am 1. Februar 1904 indirekt die Gültigkeit der alten Verträge angesprochen, indem betont wurde, dass hinsichtlich der Übertragung auf das Rittergut Schirgiswalde der Traditionsrezeß und die Partikularverfassung keine Relevanz besäßen, da dieses oberlausitzische Rittergut erst 1845 zu Sachsen gekommen ist; Mitteilungen über die Verhandlungen des ordentlichen Landtags im Königreiche Sachsen während der Jahre 1903-1904, Erste Kammer, Dresden 1904, S. 152. - Einen onlineZugriff auf die Landtagsprotokolle bietet das SLUB-Projekt „Historische Protokolle des Sächsischen Landtages": landtagsprotokolle.sachsendigital.de/startseite/ [Zugriff: 12. August 2018].

157 Mit Verweis auf die ausführliche Darstellung bei Herzog, Rechtliche Sonderstellung der Oberlausitz (wie Anm. 2) kann hier auf eine umfassendere Darstellung der kirchlichen Sonderstellung verzichtet werden. Vgl. z. B. auch SснміDт, Einschränkung der rechtlichen Sonderstellung (wie Anm. 2), S. 81-83. Die Unterschiede in den Kirchenverfassungen der Erblande und der Oberlausitz im Kaiserreich werden auch in der Dissertation von Benjamin Gallin aufgegriffen: Benjamin Gallin, Katholische Arbeiter im Mutterland der Reformation. Konfession und Arbeitsmigration in Sachsen 1871-1914 (Veröffentlichungen der Kommission für Zeitgeschichte B/134), Paderborn 2019.

158 Vgl. Herzog, Rechtliche Sonderstellung der Oberlausitz (wie Anm. 2), S. 80. 
chen Aufsichtsbehörden - Superintendenturen oder Kircheninspektionen gab es aufgrund der besonderen Kirchenverfassung in der in Sachsen üblichen Form noch nicht - fast ausschließlich durch die Rittergutsbesitzer und Stadträte der Vierstädte eingesetzt. Gerade wegen dieses unzeitgemäßen Abhängigkeitsverhältnisses gehörten „Oberlausitzer Geistliche zu den schärfsten Gegnern der Sonderverfassung ". ${ }^{159}$ Umgekehrt stemmten sich die geistlichen Stände - namentlich das Bautzener Domkapitel mit ihrem Dekan als "Seele des Widerstandes“ 160 - aber auch besonders vehement gegen eine Beschränkung ihrer Rechte.

Doch auch wenn die Sonderverfassung selbst in der Oberlausitz zunehmend auf Ablehnung stieß und als ein „Freibrief“ für die Stände galt, ${ }^{161}$ gab es im kirchlichen Bereich bis zum Ende der Monarchie keine Handhabe für staatliche Eingriffe, was der Oberlausitz noch 1907 den schon eingangs erwähnten Vorwurf einbrachte, einen „Staat im Staate“ zu bilden. Im Dezember 1915 betonte daher der sächsische Kultusminister Heinrich Beck (1854-1933), ${ }^{162}$ zu dessen Ressort auch das Kirchen- und Schulwesen gehörten, in einer Sitzung der Zweiten Kammer des Sächsischen Landtags, dass der geäußerte Wunsch, die Sonderstellung der Lausitz möglichst zu beseitigen, [...] kaum erfüllbar sein [wird], da in der Urkunde vom 17. November 1834 ja die ausdrückliche Allerhöchste Zusage gegeben ist, daß in der Religions- und kirchlichen Verfassung, welche durch den Traditionsrezeß [...] und Traditionsabschied [...] vertragsmäßig feststeht, obne vorberiges ausdrücklich erklärtes Einverständnis der Oberlausitzer Provinzialstände nicht geändert werden solle. ${ }^{163}$ Noch deutlicher hätte die hier aus der Sicht eines sächsischen Ministers vorgebrachte weitere politische Gültigkeit des Traditionsrezesses kaum formuliert werden können.

Mit dem Abdanken der Monarchie endeten dann auch die oberlausitzischen Sonderrechte. In seiner Verfassung 164 vom 1. November 1920 hob der neu gegründete Freistaat Sachsen in Paragraf 52 die Oberlausitzer Partikularverfassung explizit auf: [Absatz 1] Die öffentlich-rechtlichen Sonderrechte, die durch die Provinzial-Landtagsverfassung in der Oberlausitz [...] begründet sind, werden aufgehoben. [Absatz 2] Die öffentlich-rechtlichen Sonderrechte der Oberlausitzer Standesherrschaften und Rittergüter werden aufgehoben. ${ }^{165}$ Erst mit der Verfassung von 1920 traten die sächsischen Gesetzte nun auch ohne Zustimmung der

159 Schмidt, Einschränkung der rechtlichen Sonderstellung (wie Anm. 2), S. 82.

160 Scheuffler, Staat im Staate (wie Anm. 3), S. 31.

161 Vgl. SCHмidT, Einschränkung der rechtlichen Sonderstellung (wie Anm. 2), S. 77-79.

162 Vgl. Uwe Müller, Beck, Heinrich Gustav, in: Sächsische Biografie (wie Anm. 74).

163 Mitteilungen über die Verhandlungen des ordentlichen Landtags im Königreich Sachsen während der Jahre 1915-1916, Zweite Kammer, Bd. 1, Dresden 1916, S. 330.

$164 \mathrm{Vgl}$. Christoph Jestaedt, Die Sächsische Verfassung von 1920. Der Freistaat Sachsen - eine Republik in stürmischer Zeit (1918-1935), in: Pfeiffer, Sachsen als Verfassungsstaat (wie Anm. 85), S. 44-56, 153-156.

165 Zitiert nach: ebd., S. 156. Zu den Verfassungsdebatten im Vorfeld von 1920 vgl. auch Johannes Frackowiak, Verfassungsdiskussionen in Sachsen nach 1918 und 1945, Sonderausgabe für die Sächsische Landeszentrale für politische Bildung, Köln 2005. 
Provinzialstände automatisch in Kraft, ${ }^{166}$ und erst jetzt hatten „die Staatsverträge von 1635 und 1636 ... ihre Gültigkeit verloren" und den Weg frei gemacht, um 1925/26 auch die kirchliche Sonderstellung aufzuheben und die Oberlausitz vollends in die sächsische Landeskirche einzugliedern.167

Und wieder gab es ein Aber: Obwohl die Oberlausitzer Provinzialstände mit der Verfassung von 1920 ihrer alten Privilegien verlustig gegangen waren, blieben sie „in unveränderter Zusammensetzung als juristische Person des öffentlichen Rechts bestehen, ebenso ihr Vermögen und ihr Recht zur Verwaltung des Vermögens“. 168 Die nunmehrigen „Landstände des ehemaligen sächsischen Markgrafentums Oberlausitz" wollten den Verlust ihrer Privilegien nicht gänzlich ohne Gegenwehr akzeptieren. Ein von ihnen bei dem Leipziger Professor für Verwaltungs- und Staatsrecht Erwin Jacobi169 in Auftrag gegebenes Rechtsgutachten sprach 1921 hinsichtlich der Aufhebung der Provinzialverfassung von 1834 sogar von einem bewussten Rechtsbruch seitens der sächsischen Regierung. ${ }^{170} \mathrm{Um}$ einen Rechtsbruch soll es sich hier gehandelt haben, weil entgegen der - aus Sicht des Gutachters - immer noch voll in Geltung stehenden Oberlausitzer Verfassung die Provinzialstände nicht mit in die Verhandlungen der verfassungsgebenden Landesversammlung einbezogen beziehungsweise ihre Zustimmung nicht eingeholt worden ist. Doch selbst wenn für Ernst Jacobi die Provinzialverfassung von 1834 auch 1921 immer noch gültig war, so hätten die Landstände auch seiner Auffassung nach ihre Ansprüche kaum durchsetzen können. Dies könnte nur eine Macht erzwingen, die sich gegen die bestehenden Gewalten des Freistaates Sachsen durchsetzen würde. ${ }^{171}$ Doch eine solche unterstützende Macht sollte sich nicht mehr finden, sondern ganz im Gegenteil wurden die Oberlausitzer Landstände und deren Institutionen nach dem Zusammenbruch des Dritten Reiches von der sowjetischen Besatzungsmacht endgültig aufgehoben. ${ }^{172}$

\section{Fazit}

Seit 1635 bildete der Prager Traditionsrezess die bestimmende Grundlage für die verfassungsrechtliche Stellung der beiden Markgraftümer Ober- und Niederlau-

\footnotetext{
166 Vgl. Sснміdт, Einschränkung der rechtlichen Sonderstellung (wie Anm. 2), S. 83.

167 Herzog, Rechtliche Sonderstellung der Oberlausitz (wie Anm. 2), S. 94.

168 SснміDт, Einschränkung der rechtlichen Sonderstellung (wie Anm. 2), S. 83; vgl. auch ERWIN JACOBI, Die Rechtsstellung der Oberlausitz nach der sächsischen Verfassung vom 1. November 1920, Leipzig 1921, S. 19 f.

169 Das Gutachten von Jacobi fällt in dessen Zeit als Professor für Verwaltungs- und Staatsrecht an der Juristenfakultät der Universität Leipzig; zu seiner Biografie vgl. den „Professorenkatalog der Universität Leipzig“, online: research.uni-leipzig.de/catalogusprofessorum-lipsiensium/leipzig/Jacobi_69/ [Zugriff: 12. August 2018].

170 Vgl. Jасові, Rechtsstellung der Oberlausitz (wie Anm. 168), insbesondere S. 21-24, Zitat $=$ S. 23.

171 Vgl. ebd., S. 23 f.

172 Vgl. Sснміdт, Einschränkung der rechtlichen Sonderstellung (wie Anm. 2), S. 83.
} 
sitz innerhalb des sächsischen Staatsverbandes. Auf der einen Seite war so der Fortbestand der Sonderverfassungen der beiden Lausitzen, insbesondere deren katholische Minderheit, geschützt, auf der anderen Seite stand der sächsisch-böhmische Vertrag aber auch Reformen und Modernisierungen im Wege.

Mit der Erhebung zum Königreich 1806 pochte Sachsen zukünftig gegenüber Österreich auf seine gewonnene Souveränität und lehnte vehement die weitere Gültigkeit des Traditionsrezesses ab. Auch der Wiener Hof scheint diese Auffassung, zumindest in Bezug auf die lehnsrechtliche Stellung der Lausitzen, anfänglich geteilt zu haben, änderte innerhalb weniger Jahre aber seine Meinung und forderte weiterhin die volle Einhaltung der alten Vertragsbestimmungen ein.

Interessanterweise legte die sächsische Regierung gegenüber den eigenen Ständen der nach der Teilung von 1815 verbliebenen Oberlausitzer Gebiete eine entgegengesetzte Vorgehensweise an den Tag: Hier hielt sie sich weiterhin streng an die bestehenden Verträge und garantierte diese mit der Oberlausitzer Partikularurkunde vom 17. November 1834 sogar über die sächsische Verfassung von 1831 hinaus. Gerade die Partikularverfassung von 1834, die noch einmal ausdrücklich alle auf dem Traditionsrezess fußenden Sonderrechte der Oberlausitzer Stände wiederholte, zeigt hinsichtlich der Gültigkeit der alten Bestimmungen von 1635 eine deutliche Trennung: Alle Punkte, die aus sächsischer Sicht der eigenen staatlichen Souveränität im Wege standen - also die böhmische Oberlehnsherrschaft und die böhmischen Kirchenaufsichtsrechte - wurden als erloschen betrachtet, nicht aber die das eigene Verhältnis mit den Oberlausitzer Ständen regelnden Vereinbarungen. Der frühere bilaterale Vertrag zwischen Habsburgern und Wettinern erfuhr somit eine Transformation in einen innersächsischen Vertrag zwischen König und Provinzialständen.

Die sächsische Verfassung von 1831 integrierte zwar die Oberlausitz - mit den 1834 für den dortigen Geltungsbereich formulierten Einschränkungen - in den Gesamtstaat, hob deren alte Sonderstellung aber nicht gänzlich auf, sondern setzte sie im Rahmen der noch anerkannten Punkte des Traditionsrezesses auf eine neue rechtliche Grundlage. Auch weiterhin durfte die sächsische Regierung ohne ausdrückliche Zustimmung der Oberlausitzer Stände, die zäh an ihren überkommenen Rechten festhielten, nichts an deren Sonderverfassung ändern. Insbesondere im Bereich des Kirchenwesens und der Gesetzgebung brachte dies der Oberlausitz nicht nur den Ruf einer politischen und wirtschaftlichen Rückständigkeit ein, sondern auch, einen Staat im Staate zu bilden.

Warum die sächsische Regierung bis zum Ende der Monarchie die Oberlausitzer Sonderverfassung nicht gänzlich aufhob, war nicht Gegenstand der vorliegenden Betrachtungen. Am plausibelsten erscheint aber trotzdem gerade anfänglich eine besondere außenpolitische Rücksichtnahme auf Österreich, das als politischer, aber auch wirtschaftlicher Gegenpol zu Preußen benötigt wurde, und mit dem es sich bis 1845 hinziehende, ungeklärte Territorialansprüche hinsichtlich der böhmischen Enklaven in der Oberlausitz gab. Ein weiterer Punkt, dem spätestens mit der Zurückdrängung des österreichischen Einflusses im Deutschen Bund eine 
gewichtige Rolle zugemessen werden muss, ist das Bestreben Sachsens, für seine weitere politische und ökonomische Entwicklung ein hohes Maß an Rechtssicherheit zu schaffen. Die Sonderverfassung der Oberlausitz einfach mittels eines „Rechtsbruches“ zu beseitigen, wäre wohl kaum noch mit dem im 19. Jahrhundert in der bürgerlich-liberalen Gesellschaft aufkommenden Gedanken der Rechtsstaatlichkeit ${ }^{173}$ vereinbar gewesen.

Das politische Weiterwirken einzelner Bestimmungen des Traditionsrezesses über 1806 und 1831 hinaus scheint geradezu die Frage provoziert zu haben, ob dann nicht noch der ganze Vertrag Gültigkeit besäße. Auch auf zwischenstaatlicher Ebene konnten sich Sachsen und Österreich 1845 nur darauf verständigen, dass hier unterschiedliche Rechtsauffassungen bestanden. Auch wenn Österreich zukünftig seine beanspruchten Rechte gegenüber Sachsen nicht mehr vorbrachte, so hielten die Habsburger doch bis zum Ende ihrer Monarchie daran fest. Bezeichnenderweise gelang es selbst den sächsischen Staatsrechtlern Ende des 19. Jahrhunderts noch immer nicht, ein abschließendes Urteil zu fällen. Und auch in den sächsischen Regierungsbehörden und Ministerien herrschten bis in die Zeit des Ersten Weltkriegs hinein unterschiedliche Meinungen.

Bis zu ihrer Aufhebung durch die Verfassung des Freistaates Sachsen vom 1. November 1920 fußten die ständischen Sonderrechte in der Oberlausitz auf den sächsisch-böhmischen Vereinbarungen von 1635. Auch im gesamten 19. und beginnenden 20. Jahrhundert war der Prager Traditionsrezess in seiner 1834 rechtlich modifizierten Form die Grundlage für die Partikularverfassung der Oberlausitz, sodass ihm auch für diesen Zeitraum der Charakter eines Schlüsseldokuments der sächsischen und oberlausitzischen Geschichte zuzumessen ist.

173 Vgl. z. B. die „Ausarbeitung“ WD-1-3000-022/18 „Rechtsstaat und Unrechtsstaat: Begriffsdefinition, Begriffsgenese, aktuelle politische Debatten und Umfragen“ der Wissenschaftlichen Dienste des Deutschen Bundestags von 2018, hier insbesondere S. 6, online abrufbar unter: www.bundestag.de/dokumente [Zugriff: 12. August 2018]. 